\title{
Das hebräische Klagelied.
}

Von

Prof. C. Budde in Bonn.

In einem kurzen und gewils wenig beachteten Aufsatze habe ich vor nunmehr sieben Jahren eine kritische Uebersicht gegeben über die bis dahin vorliegenden Versuche, feste metrische Formen in der hebräischen Poesie nachzuweisen; das Resultat war Ablehnung aller bisherigen Versuche und die weitgehendste Skepsis betreffs aller in Zukunft noch zu erwartenden ${ }^{1}$ ). Dafs meine kleine Arbeit zeitgemäls, war, hat die Erfahrung seitdem bewiesen. Nicht nur konnte schon damals der Herausgeber der Studien meine Vermuthung, dafs J. Ley sein Versprechen, eine vollständige Analyse der hebräischen Gedichte nach seinem System zu geben, halten werde, bestätigen; nicht nur beschenkte uns schon das Jahr 1875 wirklich mit einer ausführlichen und reichlich durch Beispiele erläuterten Darlegung seines Systems : auch meine etwas optimistisch zweifelnde Frage, ob dieser Versuch wohl der letzte sein werde, hat ihre Antwort, eine energisch verneinende, erhalten in zwei neuen Systemen, von denen das zweite freilich nur Berichtigung und Vervollkommnung des ersten sein will ${ }^{2}$ ). Diese neuen Versuche haben mich keineswegs

1) Stud. und Krit. 1874, Heft 4. S. $747 \mathrm{ff}$.

2) Metrices biblicae regulae exemplis illustratae scrips. Bickell 1879 nebst Supplementum, vgl. ZDMG. Jahrg. XXXII, S. $701 \mathrm{ff}$. Zeitschrift f. d. alttest. Wiss. Jahrgang 2. 1882. 
zu bekehren vermocht, vielmehr glaube ich, dafs mein damaliger Hauptrgegner $\mathrm{L}$ ey der Wahrheit näher gekommen ist, da er in jedem Falle den hebräischen Texten weniger Gewalt anthut als seine Nachfolger. Doch es liegt mir diesmal fern, zu kritisiren, umsomehr, als ich mit den Kritiken jener Systeme, die mir zu Gesicht gekommen, in der Hauptsache einverstanden bin : ich will mich diesmal selbst auf das gefuhrliche Glatteis wagen, einen positiven Beitrag zur Entzifferung des so räthselhaften „Wies für das unumstöfslich sichere „Dafs" der hebräischen Poesie liefern. Derselbe soll sich darin von den meisten anderen Arbeiten auf diesem Gebiete unterscheiden, dals er keinen untrüglichen Hauptschlüssel zu allen verschlossenen Thüren desselben darbieten, sondern sich auf ein einziges, klar begrenztes Problem- beschränken wird; so will ich auch nicht mit einer Theorie beginnen, sondern die Beobachtung, das Experiment allein gelten und mir von dem Inhalt Aufschlufs über die Form geben lassen.

Wenn ich davon ausgehe, dafs in dem Buche der Klagelieder die Kunst der poetischen Form sich in besonders hoher Steigerung darstellt, so stehe ich wohl auf dem Boden einer allgemein zugestandenen Thatsache. Nur darum handelt es sich, worin vor allem diese hohe Entwicklung der Kunstform sich offenbart. Nicht, wie es nach den meisten neueren Darstellungen scheinen könnte, in der alphabetischen, akrostichischen Anordnung der vier ersten Lieder, denn diese kehrt oft genug wieder und beruht auf einem einfachen mechanischen Hand- und Kunstgriff, nicht auf organischer Weiterentwicklung der überlieferten Kंunst-

De re metrica Hebraeorum disseruit P. Gerardus Gietmann, S. J. 1880. Uebrigens ist meine Meinung, dafs schon damals alle möglichen Wege eingeschlagen waren (S. 764), durch diese Arbeiten nicht widerlegt. da die Schriften in der Hauptsache nur die S. $757 \mathrm{f}$. besprochene Idee von Merx ausführen. 
form ${ }^{1}$ ). Viel wichtiger und eigenthümlicher ist die Bildung der einzelnen Verse oder Versglieder in den Capiteln $1-4$, derjenigen Einheiten, deren 3 in cap. 1 und 2, 2 in cap. 4 unter denselben Buchstaben gestellt sind, während cap. 3 je 3 von ihnen einzeln mit demselben Buchstaben beginnt. Dals wir es hier mit Versen von ungewöhnlichem Bau zu thun haben, hat, soweit mir bekannt, Low th zuerst beobachtet ${ }^{2}$ ). Ihm sind die Verse „dimidia prope parte productiores, quam qui alias plerumque et vulgo occurrunt, media eorum mensura videtur esse syllabarum duodecim." Der Fehler der Silbenzählung, welcher hier L ow th trotz aller feinen Beobachtung den Blick für die Hauptsache verschlofs, hat noch einem der neuesten $\mathrm{Me}$ -

1) Je weniger man aus dieser Erscheinung macht, um so besser wird man thun. Die zahlreichen Hypothesen über ihren Sinn und Zweck im allgemeinen, wie boi den Klageliedern insbesondere, kann ich übergehen, da sie für ihre Bedeutung als Kunstform nichts austragen; ich kann sie durch die wohlfeile vermehren, dafs bei dem Klageliede das fast regelmärsige איכה zu Anfang eine erste Veranlassung geboten haben kann. Zurückzuweisen ist jede grundlegende Verwendung für eine Strophentheorie, wie dafür besonders So mmer (Biblische Abhandlungen S. $93 \mathrm{ff}$.) den Ton angegeben hat : die Psalmen 111 und 112 sind eclatante Beweise dagegen. In der Reihe Ps. 111, Pr. 31, 10-31, Thr. 4, Ps. 37, Thr. 2 steht die abnehmende Schwierigkeit der alphabetischen Anordnung in umgekehrtem Verhältnifs zu der wachsenden Länge des Gedichtes : diese beiden Motive entscheiden über die Stelle des alphabetischen Buchstabens, die demnächst durch blofses Abzählen ermittelt wird, weil regelmälsige Zwischenräume unerläfsliche Bedingung sind. Die Stücke Thr. 3 und Ps. 119 suchen durch Wiederholung des Buchstabens breiten Ergufs des Stoffes mit höchster Schwierigkeit des Kunststückes zu vereinigen, sie wollen gleichsam beweisen, dafs nicht künstlerische Schwäche der Grund für die Länge des Gedichtes ist.

${ }^{2}$ ) In seiner. vortrefflichen praelectio XXII (cf. auch XXIII) de sacra poësi Hebraeorum, S. $454 \mathrm{ff}$. der Ausgabe von 1770, $296 \mathrm{f}$. der Marginalzahlen. Als ich nach gethaner Arbeit nach meinen Vorgängern mich umsah, fand ich bei ihm die bei weitem beste, viel zu wenig beachtete Behandlung des Gegenstandes. 
triker gan\% denselben Streich gespielt; wir finden bei Bickoll fiir die \& ersten Capitel dor Klaggelieder ganz ebonso ein metrum dodecasyllabum", ohne jede weitcre Bemorkung "). Auch Ewald ist im wesentlichen hierbei stchen geblicben. Ihm sind die Klagrelicaler in "Langgliedern" geschrieben, von ihm mit der Chiffre ${ }_{n} \mathrm{~A}, \mathrm{~B}, \mathrm{C}^{*}$ bezcichnet, die er dahin definirt, dal's zwei kürzere Glieder $n^{a} b^{*}$ in oin lïngeres, das durchschnittlich 10 oder 11 Silben umfal'st, zusammengedriingt sind. Die Thcilbarkeit dieser Glieder, dio or in manchen Fïllen zugribt, ist ihm nur accidentell und nicht Regel, und wenn er in der Uebersetzung der Klargelieder und anderwärts vielfach durch einen Gedankenstrich einen Einschnitt hervorhebt, so unterliifst er dies fast ebensooft oder setzt ihn an falscher Stelle. Dafs er in cap. 5 denselben Vers, nur in einem einzelnen Gliede, erkennt ${ }^{2}$ ), beweist, wie wenig er sein Wesen ergründet hat. Sicher hat ihm seine künstliche, auf $\amalg$. Sam. 1, 19-27 begründete und auf das Buch der Klagelieder angewandte Theorie von dem sinkenden Bau der Liedwenden" im Klagelied die Aufgabe erschwert ${ }^{3}$ ). Eine im Gauzen richtige Auffassung der Versstructur scheint zuerst d e W et te zu geben ${ }^{4}$ ). Er erkennt, dafs jedes Versglied noch eine Cïsur, dem Sinne (und den Accenten) nach aufweist, sodafs sich vielfach ein Unterparallelismus bilde. Ueber die Stelle der Cäsir, das Verhältnifs der durch sie entstandenen Abschnitte zu einander, gibt er keinen Aufschlufs, ebensowenig Delitzsch in seiner Definition des „Cäsurenschema (richtiger : des diäretischen Schema) ${ }^{\star 5}$ ). Die früheste

1) Bicke11 S. 6. 34,ff.

2) Er würde also das Schema für capp. 1-3 mit „A B $C^{u}$, für 4 mit ${ }_{n} \mathrm{~A} \mathrm{~B} \mathrm{~B}^{4}$, für 5 mit ${ }_{n} \Lambda^{4}$ wiedergeben.

$\left.{ }^{8}\right)$ Vgl. Dichter des alten Bundes 2. Aufl. I, 2. S. 325 ff. I, 1. S. $129 ; 120$ f.; 151 f.; auch 1. Aufl. 1. S. 142.

4) Comm, zu den Psalmen. 4. Aufl. 1836. S. 55 f.

5) Bibl. Comm. Psalmen 3. Aufl. S. 19, noch weniger bestimmt Graf in Schonkel's Bibellexicon Bd. III, S. 209. Aehulich Kamp- 
Bemerkung darüber finde ich bei Keil ${ }^{1}$ ), dafs die Stichen in der Regel noch durch eine Cäsur des Gedankens in zwei Absätze von ungleicher Länge getheilt seien; ein Rückschritt gegen de Wette liegt in dem vorsichtig beschränkenden "in der Regel" ${ }^{\mu}$. Erst Ley, soweit mir bekannt, spricht es für diesen Vers bestimmt aus, dafs das zweite Hemistich kürzer als das erste gehalten sei; er findet diesen Vers besonders geeignet gerade für das Klagelied, er ordnet ihn seinem System ein unter dem ebenso pompösen als milsverständlichen und im Grunde unrichtigen Namen des elegisclien Pentameters. Endlich Gietmann spricht von einem versus hendecasyllabus und weiter: ${ }_{n}$ post tertiam arsim vel proximam thesim caesura versum dividere solet" ${ }^{2}$ ).

Ich gehe zu eigener Formulirung des Ergebnisses über. In den 4 ersten Capiteln des Buches der Klagelieder bildet die überall gleichwerthige Formeinheit ein kurzer Vers, dessen erste, durch einen Einschnitt des Sinnes abgegrenzte Hälfte die Länge des vollen Versgliedes eines regelrechten kurzen Verses aufweist, wie er etwa im Buche Hiob herrscht, während die zweite Hälfte, regelmälsig kürzer gehalten, als das verstümmelte zweite Versglied gelten kann. Für diese zweite Vershälfte ist, da sie eine Wortgruppe bleiben mufs ${ }^{3}$ ), als das Minimum an Länge die Verbindung zweier

hausen in Bunsen's Bibelwerk III, S. 568, Nägelsbach in Lange's Bibelwerk, Klagelieder S. VIII.

1) Hävernick's Einleitung in das A. T. Bd III, S. 512. 1849. Daraus scheint Theniu' ' Charakteristik (Kurzgef. ex. Hdb. zu den Klageliedern. 1855. S. 124) fast wörtlicb entnommen zu sein. Aebnlich noch v. Orelli in Herzog's Realencyklopädie, 2. Aufl. Bd. VI, S. 527.

${ }^{2}$ ) So S. 35, wäbrend er \$. 58, wo das Metrum noch einmal genau beschrieben wird, von versus enneasyllabi redet, der Căsur gar nicht gedenkt und auch in c. 4 je 3 Verse unter einen Buchstaben des Alphabets gestellt sein lälst.

$\left.{ }^{3}\right)$ Dies einzige Postulat, das ich aufstelle, scheint mir aus der Sache hervorzugehen, sobald es feststeht, dafs Sinneseinschnitte ent- 
selbstïndiger Worte gegreben : daraus ergibt sich als das Minimum fur die erste Hälfte ein Umfangr von drei Worten. Das Verhältnifs von $3: 2$ ist also das erste, welches der Absicht, ein kürzeres Versglied dem ersten lïngeren folgen zu lassen, entspricht; doch sind damit andere Verhältnisse und lïngere Verse, wie $4: 2,4: 3$ u. s. w. keineswegs ausgeschlossen.

Der Nachweis dieses Sachverhaltes wird am besten mit cap. 3 beginnen, denn dort sind diese Verse am regelmärsigsten ausgebildet, dort steht jeder für sich allein auf eigenen Fülsen. Denn wenn sich ungezwungen manche der unter demselben Buchstaben vereinigten Triaden auch dem Sinne nach zusammenschlielsen und von der Umgebung loslösen, so bedarf doch keiner der einzelnen Verse paralleler Ergänzung, und gewissenhafte Sinneseintheilung wird z. B. nach den Versen 11,13, 16, 41, 47, 59 Theilstriche setzen müssen, welche die Gruppe eines Buchstabens durchschneiden. Unter den 66 Versen dieses Capitels finde ich nun nur 6-7, die dem oben aufgestellten Schema nicht genau entsprechen; aber diese Verse sind schwerlich alle in der ursprünglichen Gestalt erhalten. Vers 31 lälst gar keine Theilung zu, es fehlt das Object zu לא יונח : ich vermuthe, dals es ausgefallen, vielleicht בני איש, übersehen, weil es in der folgenden Zeile, Ende des Verses 33 wiederkehrt. Der Theilstrich wäre dann nach לעולם zu setzen und der Vers in Ordnung. Vers 13 hat nur 4 Worte; es .wird nach כליו ein oder geradezu nach Ps. 7, 14 כלי מות ausgefallen sein, dessen Ergänzung den Vers aufs schönste herstellt. Mit Vers 23 steht es ebenso; auch um der Selbständigkeit des Verses willen empfiehlt sich die Annahme, dafs das 'Wort רחעיו, womit v. 22 schliefst, auch an der zweiten Stelle von v. $23 \mathrm{zu}$ lesen ist.

scheiden : ich lege deshalb auch eine Schätzung der Länge nach Worten als die einfachste und übersichtlichste zu Grunde, ohne damit eine Theorie aufstellen zu wollen. 
Ist nun bei so vielfachem Ueberwiegen von Versen, die genau dem aufgestellten Schema entsprechen, jeder Zweifel an der Absicht ausnahmsloser Verwendung desselben unzulässig, so folgere ich aus den noch verbleibenden unregelmälsigen Versen leichte Modificationen des Schema's, die der. Dichter für erlaubt hielt.

1) So zuerst v. 56. Ich möchte da nicht mit LXX und Ley das letzte Wort streichen, vielmehr ist das erste Versglied (mit אונך schliefsend) zu lang gerathen, aus zwei קולי den Ordnungsbuchstaben gewann, und doch vom Fleck kommen mufste. Solche Verse sind in den übrigen Capiteln : cap. $2,13^{\text {a }}$; cap. $4,18^{\text {b }}$. $20^{\text {a }}$.

2) In v. 15 stehen nur 2 Worte im ersten wie im zweiten Versgliede; aber durch die besondere Länge und Wucht derselben ist dem ersten Halbvers sein Uebergewicht gesichert, der Zweck erreicht. Hieraus erkläre ich : cap. $1,1^{\text {b. c. }} 4^{\text {c }} .9^{\text {b. }} \cdot 13^{\text {c. }} .14^{\text {b }} .17^{\text {c. }} .18^{\text {c }} .19^{\text {a }}{ }^{\text {b }}$; cap. 2 , $12^{\text {b. }}{ }^{\text {c. }} 21^{\text {b }}$; cap. $4,5^{\text {n }}$. $13^{\text {b }}, 17^{\text {b }}$.

3) Vers 20 und 27 haben mit Recht den Hauptaccent bei dem zweiten, nicht dem dritten Worte : dem Sinne nach ist das erste Versglied das kleinere, nicht das zweite. Für solche sehr seltenen Fälle halte ich es für wahrscheinlich, dals der Dichter dem Leser zugemuthet hat, in dem gewohnten Tonfall weiterzulesen, sodafs der Halt erst nach dem dritten Worte eintritt und der Rhythmus mit dem Gedanken in leichte Collision kommt. Ich nehme dasselbe an für die Verse : cap. $1,10^{c}$. $13^{a}$; cap. 2, $8^{\text {b }}{ }^{1}$ ). Fürchtet man durch diese Annahme das Princip zu gefährden, so

1) Doch ist nicht überall nach den Accenten zu gehen. So scheinen mir 2, 20. 9c dem Schema zu entsprechen, ebenso 3, 32, anders als Ley. Uebrigens kommt die Annahme unter 3) auf etwas ähnliches heraus wie das, was Ley S. 80 Compensation nennt. 
mul's auch in solchen Fiallen auf Textverderbnifs oder Verstofse gegen den gewollten Rhythmus geschlossen werden ${ }^{1}$ ).

Nun zu. cap. 4. Da bedarf vor allem v. $15 \mathrm{der} B e-$ richtigung, die schon durch die allerseits empfundene exegetische Schwierigkeit gefordert wird. Unrichtig streicht (durch Einklammerung) Ley die Worte קראו למו סורו and setzt dann den Haupttheilstrich bei נע, die Cäsuren bei תגוים Durch diese Theilung wird der Sinn entstellt und das erste Glied des 2. Verses zu kurz. Vielmehr ist אמרו בגוים Glosse, die eine bestimmte Auffassung des schwierigen Verses b vermitteln will. Vers a schliefst mit תגעו, sein Einschnitt liegt bei למו העו Vers b, bei. eingeschnitten, kann als Rede des Subjectes von קראו in verächtlicher Abwendung von den Flüchtigen, oder auch als Rede des Dichters verstanden werden. Vers $14^{\mathrm{b}}$ scheint verstïmmelt zu sein, vielleicht hat er in irgend einer Weise das Subject von קראו eingeführt; doch enthalte ich mich jeder Conjectur. - In v. 18 wird man vor 18 ein $\mathrm{zu}$ ergänzen haben ( $\nabla$ gl. 3, 52), dessen Ausfall bei ḋrei mit y beginnenden Worten leicht erklärlich ist. - In $\nabla .1^{\text {a }}$ und 13" könnte' man annehmen, dafs das logische Uebergewicht des ersten Gliedes, beruhend auf den überschiefsenden, zu b zu ergänzenden Satzgliedern איכה und מן, im Sinne des Dichters das Gleichgewicht der Wort- und Silbenzahl aufheben soll. Es bleiben dann noch $6^{\circ}$ und $19^{\circ}$, die in ihrer jetzigen Gestalt gegen dàs Schema gleich lange Glieder aufweisen. Im schlimmsten Falle bleiben unter 44 Versen 30, die dem strengsten, nicht modificirten Schema entsprechen : dafs dasselbe beabsichtigt ist, kann daher nicht bezweifelt werden, und dafs einst sämmtliche Verse aus des Dichters Hand dieser Absicht entsprechend hervorgingen, ist mehr als wahrscheinlich.

1) Ich werde diese. Modificationen des Schema von jetzt an einfach mit Nr. 1), 2), 3) anziehen. 
In cap. 2 zähle ich höchstens 9 Verse unter 67, ohne die unter 1) bis 3) aufgezählten 5, die zu Bedenken Anlals gäben; aber gerade hier lälst sich überall eine ursprünglich regelmälsige Form wahrscheinlich machen. Der überschüssige v. 19d ist von ' הע an su streichen, Glosse aus $2,11^{\mathrm{c}} ; 4,1^{\mathrm{e}}$ ). Die in $19^{\mathrm{c}}$ genannten Kinder sind schwer- lich schon todt. Dals v. 18 beschädigt ist, wird fast allgemein anerkannt; statt aller bisherigen Vorschläge empfehle ich, die Stelle der Worte 'ימם ומה בת-y' und wechselweise zu vertauschen, sodafs die Uebersetzung lautet: „Ihr Herz schrie zum Herrn : bei Tag und bei Nacht Lafs stromweis rinnen die Thränen : Du Mauer der Tochter Zion“. Die dritte Person in לִָּּם ist leicht erklärt; die Umgestaltung ist geschehen, um die neue Gestalt der personificirten Stadtmauer unverzüglich einzuführen. In $4^{\text {c fehlt }}$ deutlich das zweite kürzere Glied, denn gegen die Accente ist ' באהיל בח־y bu b als zweites Glied zu ziehen : zu c wäre etwa חרון אפו $(4,11)$, durch gleichen Anfang und Schlufs mit in empfohlen, oder ähnliches zu ergänzen. In $4^{\mathrm{a}}$ streiche ich כצר (vgl. Ps. 7, 13 ), unter Verkennung des Rhythmus als Parallele zu כאויב hinzugesetzt. In $9^{\text {म }}$ dürfte ושפר zu streichen sein, vielleicht Ergänzung eines dittographischen בר von dem folgenden בר $15^{\mathrm{c}}$ streicht schon Ley richtig die erklärende Glosse שיאמרו, obgleich den Vers nicht gefährdend. In $14^{\circ}$. setzt Ewald richtig die Cüsur bei משטאות, das als stat. abs. zu lesen sein wird; die folgenden Worte sind Apposition. Im ersten Gliede von $2^{b}$ scheint ein-zweites Verbum ausgefallen zu sein, das in a und c zu finden ist und auch hier das Uebergewicht herstellen würde. Endlich iu $12^{\mathrm{a}}$ ist mir das im Munde der Kinder und Säuglinge dringend verdächtig, aber seine Einschiebung leicht erklärt bei der so weit über-

1) So schon Ewald. 
wiegrenden Koppelung von iג und שירוg (vgl. übrigens Ps. 78, 24). Dal's diese Vermuthung das Richtige trifft, beweist die Peschîtâ, die ihre Kinder, mit dem Wein nicht zutrieden, als drittes auch noch Oel fordern läfst (vgl. die 3 in derselben Reihenfolge schon Hosea 2, 10 und sehr h:iufig sonst).

Capitel 1 bietet keine grofsen Schwierigkeiten. Dals v. 1 die Accente zu verlassen sind, ist längst erkannt; es ergeben sich drei regelrechte Verse, vor denen allerdings b und c oben unter 2) aufgeführt werden mulisten. Vers 7 hat 4 Verse, aber b ist unecht von (vgl. 10a. 11" $; 2,17^{\mathrm{b}}$ ); die mit בנפל beginnende Zeitangabe be-

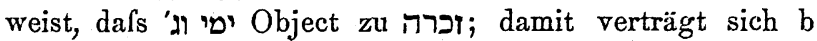
nicht $\left.{ }^{1}\right)$. Der Vers scheint auch sonst gelitten zu haben, da die ersten Glieder von $7^{n}$ und a $z u$ kurz sind. Doch soll die Möglichkeit einer Ausnahme oder eines Verstufses besonders bei a nicht geleugnet werden. In $14^{\mathrm{c}}$ helfen endlich einmal die LXX. Sie übersetzen : $o \tau \iota \varepsilon \delta \omega \varkappa \varepsilon$

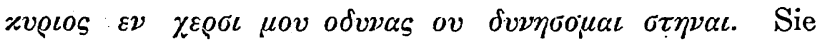

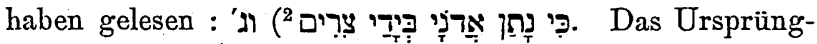

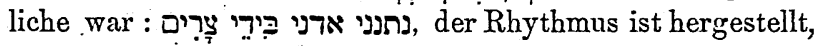
und der Sinn -entschieden besser ${ }^{3}$ ). Auch in $16^{\text {a }}$ helfen die LXX, indem sie ebenso wie Hieron. das eine עיני streichen. In v. $2^{n}, 4^{n}, 8^{n}$ ist das zweite Glied etwas schwer gerathen, doch dürften die Partikeln על-בן ,מכלי ,על nicht als vollwichtig erachtet sein, wie oft. Dazu kommt

1) So schon Ewald.

2) vgl. צריה def. auch. I. Sam. 4, 19. Dort übersetzen LXX freilich wie auch Jes. 13,$8 ; 21,3$ mit $\omega \delta \iota v \varepsilon \varsigma$, aber auch

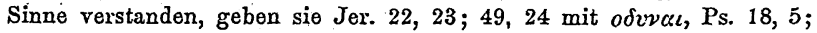
116,3 mit $\omega \delta\llcorner\nu \varepsilon s$.

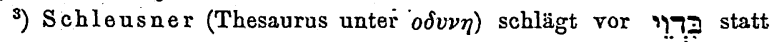
נתגני statt, so auch Rosenmüller; das erste läfst kein Aequivalent für $\varepsilon \dot{\nu} \chi \varepsilon \varrho \sigma \iota \nu \mu \nu v$, gegen das zweite spricht die Wortstellung. 
die verhältnilsmälsig grolse Zahl nicht ganz genauer Verse, die oben, 10 unter 2), 2 unter 3) aufgeführt sind. Man möchte fast vermuthen, dafs dem Dichter hier die Durchfïhrung etwas sauer geworden; immerhin bleiben, wenn alles Angeführte zurückgewiesen würde, nur $20 \mathrm{Ab}$ weichungen unter 66 Versen. An diesem Capitel ist Le y's - Kunst gescheitert; wie es scheint, durch die falsche massoretische Abtheilung von v. 1 verleitet, zerschneidet er jeden Vers des Capitels in die unmöglichsten Distichen ${ }^{1}$ ). Das Beispiel ist sehr lehrreich, weil es zeigt, was alles bei der Le y'schen Methode möglich, wie wenig ihr zu trauen ist.

Von selbst widerlegt sich nun auch Ewald's Aufstellung, dafs cap. 5 in denselben Versen geschrieben sei wie die übrigen Capitel. Nur die Verse 2, 3, 14 entsprechen zufällig dem Schema jener Stücke, wie das auch anderwärts gelegentlich vorkommt ${ }^{2}$ ).

Mit dieser Analyse des Buches der Klagelieder glaube ich die aufgestellte These über die in den vier ersten Capiteln angewandte Versform in ihrem vollen Umfange bewiesen zu haben. Nicht in der Regel" oder "meistens" sind die Verse derart gestaltet, sondern ausnahmslos hat der Dichter solche Verse bilden wollen. Die Folgezeit hat diese Absicht bald übersehen, daher die Eingriffe in den ursprünglichen Text, die fast ausnahmslos den Rhythmus schädigen : dies nachzuweisen, nicht eine vollständige Textkritik des Buches zu geben, war der Zweck meiner Anmerkungen.

Es fragt sich nun, was den oder die Verfasser ${ }^{3}$ ) jener Stücke bewogen, gerade diese Versform zu wählen : ist sie überliefert oder für diese Stücke geschaffen; ist sie

1) S. $245 \mathrm{ff}$.

2) Ley nennt solche Verse katalektische Hexameter (S. 51).

${ }^{8}$ ) Die Frage nach der Herkunft der Klagelieder wird weiter unten kurze Behandlung finden. 
frei, vielleicht gar willkürlich gowiihlt, oder lagen bestimmonde Griinde vor, gerade solche und keine andercn Rhythmen hicr anzuwenden? Die Antwort darauf kann nur dann gegeben werden, wenn es glückt, andere Stücke in derselben Versform zum Vergleiche heranzuziehen.

Das Stück, wclches am klarsten bei grofsem Umfang dieselben Rhythmen zeigt, ist das Lied in Jes. 14, 4-21. Die wenigsten Ausleger oder Metriker wissen etwas davon, wenn auch mehr als einer einen kunstvollen Strophenbau darin nachzuweisen sucht ${ }^{1}$ ). Gietmann dagegen erkennt hier seinen versus hendecasyllabus, dem er auf S. 35 auch Thr. 1-4 zuweist; Ewald sieht hier, was bei seiner Behandlung der Klagelieder nicht zu Tage tritt, dals das zweite Glied der Langglieder unverkennbar kürzer ist. Das sind die einzigen Neueren, bei denen ich Einsicht in die Sachlage gefunden habe.

In der That ist der Versbau genau derselbe wie in Thr. 1-4 und mit peinlichster Sorgfalt durchgeführt. Wenige kritische Anmerkungen werden genügen ${ }^{2}$ ). In v. $8^{\prime}$ sind entweder die beiden Versglieder umzustellen, so-

1) Hicr einige Schemata derselben. Drechsler findet 2 Hauptreihen, v. $4^{\mathrm{b}}-11,12-21$, jede von 3 Strophen ${ }_{n}$ mit regelmälsig wechsclndem Rhythmus $(3,2,3 ; 4,2,4)^{\text {c. }}$. Also v. $4^{\text {b }}-6,7-8,9-11$; $12-15,16-17,18-21$. - Ewald findet 5 Strophen, jede von 7 längeren Gliedern oder kurzen.Versen, mit Ausnabme der letzten, die entsprechend dem Kunstbau des Klageliedes nur 5 hat; er theilt ab : v: $4^{\mathrm{b}}-8,9-11,12-15,16-19,20-21$. (Propheten 2. Ausgab. Bd. 3 . S. 19 f.). - E. Meier findet 5 Strophen: $\mathbf{3}-6,7-10,11-12,13-17$, 18-23. Den Irrthum Meier's, der Eingangs- und Schlufsformel zum Liede hinzuzieht, theilt, was die letztere angeht, auch $\mathbf{K a m p}$ hausen (Bunsen Bbw.), der 6 Abschnitte macht : 4b $-8,9-11$, $12-14,15-17,18-20,21-23$.

2) Ein Beispiel falscher Textkritik gibt E. Meier, indem er von

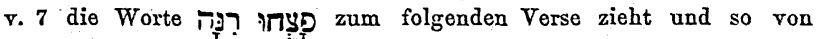
v. 7 nur ein Versglied übrig läfst, v. $8^{a}$ zu einem gewöhnlichen, gleichschwebenden Verse macht. 
dals ein ganz regelrechter Vers entsteht, oder der Vers ist nach 3) mit blofs rhythmischer Cäsur nach על zu lesen. v. 10 ist nicht mit Ewald als 33 . Vers zu zählen, sondern ebenso als Einführung des Liedes nicht mitzuzählen wie $4^{\text {a }}$. Er könnte zur Verdeutlichung der Situation erst später eingeschoben sein. Vers $17^{b}$ ist verstümmelt - (auch Ewald constatirt seine Kürze); ich wage, ihn aus v. $18 \mathrm{zu}$ emendiren. Dieser hat das Athnach richtig bei איש כביתו schliefsen; das folgende בכבוד כל כל ist überflüssig und immerhin auffallend, anders als $\mathrm{Hi}$. 30,23 und משכן in Jes. 22, 16. Mir scheint, dafs es in der Form איש לביתו für ביתה, für welches sich in der griechischen und syrischen Uebersetzung kein Aequivalent findet, als verstümmelter Ersatz zu streichen wäre. Es ist dies nicht die einzige Umstellung in diesem Zusammenhang, denn Ewald hat ganz richtig die Worte כפגר מובם vom Ende des v. 19 gleich hinter das Athnach desselben Verses gesetzt, den Rest des Verses als erstes Glied zu v. 20 gezogen und so Sinn und Rhythmus zugleich hergestellt. Der hergestellte v. 20a ist im zweiten Gliede etwas schwer, eine Schädigung in diesem Zusammenhange nicht unwahrscheinlich; vielleicht ist statt אתם בקבורה zu lesen : בקבורתם, vgl. Gen. 49, 6. - In v. $21^{\text {b }}$ ist wohl aus פנר das streichen, wofür als, wenn auch nicht ganz sichere, Stütze

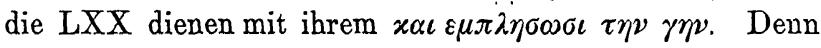
wie sonst meistens, übersetzen sie auch im B. Jesaja das פִני getreulich, so in der einzigen genau parallelen Stelle

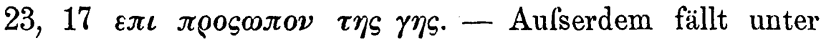
2) v. $9^{c}$, vielleicht auch $12^{b}$, wenn nicht in seinem ersten Gliede ein Wort ausgefallen ist.

Ist nun der beabsichtigte Bau dieses Stückes so unzweifelhaft klar, so verdient noch besonders hervorgehoben zu werden, wie scharf dasselbe von dem Vorhergehenden und Nachfolgenden sich abbebt. Es stelit mitten in dem 
grofsen /usammenhang cap. 13,1 bis 14, 23. Aber die ganze erste Rede des Propheten, 13, 1-1.t, 2 ist in Versen mit fast ausnahmslos gleichschwebenden kurzen Gliedern geschrichen "), und die Einleitung 'des Liedes in v. 3-4* wie der Abschlufs des Propheten in v. 22-23 sind in prophetisch gehobener Prosa gehalten, die mit diesem Rhythmus nichts zu thun hat. Nur das Lied sclbst, das dem Volke in den Mund gelegt wird, und natürlich die eingelegten Worte der Könige im Scheol ergehen sich in jenen Rhythmen.

Der Grund dafür kann nur in dem eigenthümlichen Charakter dieses Stückes liegen, der jene Form dem Verfasser als die geeignete an die Hand gab. Dieser Charakter aber ist der des Klageliedes. Denn ein Klagelied ist das Stück, da es : einem Verstorbenen nachgerufen wird, und es beginnt sogleich mit dem 7 's des .Klageliedes, das noch einmal in v. 12 die Klage von neuem anhebt. Gerade durch den Contrast zwischen der ironisch angewandten elegischen Form und dem höhnischen Triumphe des Inhalts erhält das Lied seine ätzende Schärfe. Ein Klagelied haben schon die LXX darin erkannt, indem sie an dieser einzigen

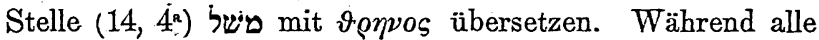
Neueren, soweit mir bekannt, dies übersehen, macht $\mathrm{L}$ o w th darauf aufmerksam und gibt die Erklärung dafür in den sehr verständigen Worten : „Offenbar sahen sie die hier eingeschaltete Rede als ein poetisches Stück an, und zwar von der elegischen Art; sei's nun wegen des Inhalts, weil es ein Lied vom Fall und Tode des Königs von Babylon ist; oder wegen des Baues der Verse, die von der längeren Art sind, gleich denen in den Klageliedern Jeremiä, die bei

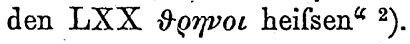

1) Nur wenige Verse verfallen wie in Thr. 5 in den Ley'schen "katalektischon Hexameter."

2) Lowth Jesaias übersetzt von Koppe, 1. Bd. S. $218 \mathrm{f}$. Den elegischen. Charakter betont übrigens auch Drechsler unter Hinweis auf das 
Damit ständen wir vor der Möglichkeit, dals der spätere Verfasser von Jes. 14 die Kunstform eben von dem Buche der Klagelieder, durch das sie eingebürgert worden, entlehnt hätte. Aber Ewald meint ein anderes Stück als Muster annehmen zu müssen, bei dem er zuerst diese Gestalt zu finden glaubt, Ez. 19. Wir werden damit auf eine ganze Gruppe solcher Stücke hingewiesen. Ezechiel verwendet eingestandenermafsen die Form des Klageliedes in einer Reihe von Stücken in mehr oder minder übertragenem Sinne $\left.{ }^{1}\right)$. Sechs Stücke sind bei ihm als קינה angekündigt (vgl. 19,$1 ; 26,17 ; 27,2 ;$ v. $32 ; 28,12 ; 32,2$ ), und zweimal wird auch in der Schlufsformel das Stück wieder als solches bezeichnet (vgl. 19, 14; 32, 16); eines, 32, 17 ff., wird durch das Zeitwort נהה wenigstens dieser Gruppe angenähert. Und sie alle, so muls ich behaupten, tragen denselben formellen Stempel, der an dem Buche der Klagelieder und Jes. 14 nachgewiesen wurde, allerdings nicht überall gleich scharf und schön ausgeprägt, aber doch so, dafs sich erkennen läfst, wie Ezechiel überall dieses Schema als das gebührenderweise zu befolgende Muster gegenwärtig war.

Die Reihe eröffnet cap. $19:{ }_{n} \mathrm{Du}$ aber, hebe an ein Klagelied auf die Fürsten Israels und sprich.u. s. w. " Es ist ein wirkliches, ernstgemeintes Klagelied, wie Smend richtig betont, auf zwei Fürsten, die als solche todt sind; auslaufend in ein anticipirtes, prophetisches auf einen dritten, mit dem zugleich Stadt und Volk sterben mufs (v. 10-14) ${ }^{2}$ ). Fast überall, sagt $\mathrm{Ewald}$, brechen darin die Verse in der Mitte derart auseinander, ${ }^{2}$ dals die zweite

1) Von 8 Stellen für das Verbum קונו finden sich 4, von 18 für קינד 10 bei Ezečhiel.

$\left.{ }^{2}\right)$ So mindestens die Voraussetzung des Stückes. Ob dasselbe erst nach Zerstörung Jerusalems niedergeschrieben ist, kommt hier nicht in Betracht. 
Hiilfte rasch abgebrochen nur wie ein vergehender kurzer Nachklarig scutzend folgt." Ich finde darin unter 28-29 Versen mindestens 16 ganz dem aufgestellten Schema entsprechend. Daneben kann man $2^{\mathrm{a}}, 4^{\mathrm{b}}, 7^{\mathrm{a}}, 11^{\mathrm{b}}$ nach 2) wohl noch gelten lassen; wenn aber vielleicht schon bei diesen die Ursprünglichkeit des Textes bezweifelt werden mufs, so ist für andere Abweichungen entschieden der schlechte Zustand desselben verantwortlich $\mathrm{zu}$ machen. Einige Andeutungen mögen hier stehen. Vers $2^{\text {b }}$, nach dem Athnach, ist beschädigt; wahrscheinlich ist vor ה ein zweites רכצה, = dem Schlufswort von $2^{\text {a }}$ ausgefallen, vgl. das doppelte יבאה v. $9^{\text {b }}$ und ähnliche Wiederholungen. Ebenso ist $9^{\mathrm{n}}$ unvollständig, worauf schon das störende ' בם' בinweist, wovon die Peschitâ nur das erste Wort wiedergibt; eine plausible Wiederherstellung weifs ich nicht zu bieten; die übrigen Glieder sind dann in Ordnung, mit ויבאה beginnt b, mit ל ל C. C. In $\nabla .10^{\mathrm{a}}$ ist Sinn und Rhythmus bei Smend's Verbesserung Vers 12 ist auch abgesehen vom Rhythmus nicht in Ordnung. Liest man mit Ewald und Smend מטות, so macht das Suffix in אבלתה neben Schwierigkeiten. Es ist vielmehr das schliefsende 1 von ויבש zu ziehen, das von התפרקו als dittographisch oder nach dem folgenden Verbum ergänzt zu streichen; die beiden Verba sind dann zum Vorhergehenden zu ziehen und bilden das zweite Glied eines mit ורוח beginnenden guten Verses. Ob ferner $12^{\mathrm{c}}$ noch einmal mit ויבש begonnen hat? Es bleiben dann noch als zu gleichschwebend gebaut $11^{\mathrm{c}}$ (auch ${ }^{\mathrm{b}}$ ?), 12a, 13 , vielleicht alle durch Hinzusetzung oder Auslassung einés Wortes verstümmelt; während die zwei V'erse in 14 wieder ganz regelrecht abschliefsen. Uebrigens ist es fraglich, ob Ezechiel selbst hier, in diesem so schönen und kunstvollen Liede, das Schema so regelmälsig hat durchführen wollen und können, wie die Verfasser von Thr. $1-4$ und 
Jes. 14. Das Schema selbst ist als mal'sgebend nachgewiesen.

Das nächste als Klagelied bezeichnete Stück ist nur von geringem Umfang; es umfalst einschliefslich der Einleitung nur die Verse 15-18 des 26. Capitels. Hier ist es eine officielle Leichenklage über den Fall von Tyrus, unter Beobachtung von Trauerceremonien angestimmt von den Fürsten des Meeres. Diese Einleitung reicht von v. 15 bis in den 17. Vers hinein : erst nach dem ואטרו לך tritt mit dem charakteristischen איך das eigentliche Klagelied ein, und - sogleich begegnen uns wieder die scharf zugeschnittenen Verse unseres Schema, deutlich zu verfolgen bis zum Schlufs von v. 18, wo der Prophet mit einem ᄁdenn also spricht der Herr Jahve ${ }^{*}$ das Wort zurücknimmt und in ruhigen, gleichschwebenden Versen fortfährt. In 5 Versen verläuft das kurze Liedchen. Der erste schliefst mit מים מהליל, sein erstes Glied mit Textänderung

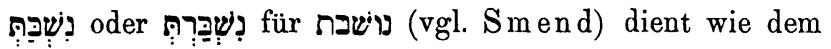
Sinne so auch dem Rhythmus, da ohne sie der Vers zwei gleich schwere Sinneseinschnitte aufwiese. - Der letzte Vers ist verstümmelt, da vom zweiten Gliede nur das Wort מצאתך übrig ist. Die Uebersetzungen gehen hier weit auseinander. Die LXX lassen den ganzen Vers $18^{\mathrm{b}}$ aus. Bei der Uebersetzung der Vulgata ist für הארוּצִי die Zeile „eo quod nullus egrediatur ex te zweifelnde Wiedergabe von מצארך sein. Die Peschîtâ

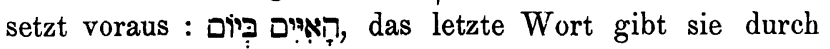
die syrische Transscription von מפלתן, wie im ersten Gliede, das i davor fehlt. Ebēnso ist das אישר ganz ausgefallen. Daran wird anzuknüpfen sein. Ich lese entweder :

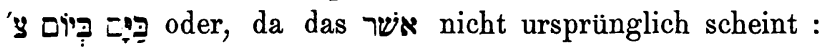

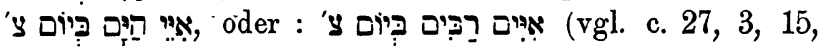
Ps. 97, 1). Die erste Fassung ist die leichteste, doch läfst sich das אשר בים gerade aus der Absicht, den Doppelsinn von אי" glossirend hervorzuheben (vgl. Smend zu der Zeitschrift f. d. alttest. Wiss. Jahrgang 2. 1882. 
Stclle), erkliiren. Dic übrigen Verse sind in bester Ordnung.

Wenige Verse weiter, 27, 1, erhält der Prophet selbst den Auftrag, ein Klargelied über Tyrus anzustimmen. Die beruhmte, kulturhistorisch und geographisch so wichtige Schilderung des Handels und Reichthums ron Tyrus und seines jühen Sturzes ist gewifs mit ihren endlosen Aufziillungen ein wenig dankbares Thema für ein in bestimmte, fein gegliederte Kunstform gegossenes Lied. Und doch ist auch unser Capitel ganz nach dem Schema gebaut, unermüdlich hat Ezechiel mit dem Stoff gerungen, durch das ganze lange Capitel hindurch; unter 64 elegischen Versen ${ }^{1}$ ) zähle ich nur etwa 13, die nicht wenigstens äufserlich dem Schema genau entsprächen. Will man sich mühelos davon überzeugen, so lese man von v. 26 an, wo die Schilderung des Marktes zu Ende ist und die weit poetischere des Sturzes beginnt. Man wird von da an bis zu Ende mit alleiniger Ausnahme zweier etwas zweifelhaften Verse, die in $\nabla .33$ vereinigt sind ${ }^{2}$ ), lauter ganz regelmäfsig gebaute Verse lesen, 23 an $\operatorname{der} \mathrm{Zahl}{ }^{3}$ ). Um sich zu überzeugen, dals es im übrigen Theile des Capitels ebenso steht, beginne man etwa mit $\nabla .7$ und lese bis $\nabla .13$ incl., man wird dort 14 Verse finden, wenn man als ihren Schlufs jedesmal Athnach und Soph Pasuq nimmt, die Cäsur jedesmal nach dem Zaqeph-Qaton, einmal in $7^{\mathrm{b}}$ nach dem Tiphcha eintreten lälst. Die ersten Glieder sind oft seltsam gespreizt wegen der Aufzühlungen, für die zweiten weifs Ezechiel stets 2 bis 3 Worte zu finden, bis zu formel-

1) $\mathrm{Zu}$ beginnen ist wohl mit' צור וצ mit 2 uuklaron Versen.

2) Vielleicht sind darin je in dem zweiten Gliede die Worte רבים und עלכי späterer Zusatz.

s) $\mathrm{Ob}$ der letzte, $=28,19^{\mathrm{b}}$, absichtlich zu gleichschwebendem Rhythmus zurückkehrt oder feste Formel ist, lasse ich dahingestellt. 
haft wiederkehrenden Abschlüssen. Nur zweimal, in v. 18 und in v. $23 \mathrm{f}$. scheint Ezechiel, wenn nicht Textbeschädigung der Grund der Unordnung ist, die Geduld verloren zu haben : die 2 und 3 Verse, die in diesen Abschnitten stecken müfsten, sind wohl nicht mehr daraus zu gewinnen. Die Thatsache der Anwendung unseres Schema ist nicht anzuzẅweifeln, darum verzichte ich auf die Einzelanalyse. Interessant ist, dafs auch hier wie in Jes. 14 ein zweites Klagelied eingeschoben oder vielmehr angehängt ist, dessen Einleitungsworte (v. 29 ff., besonders $32^{\mathrm{a}}$ ) jedoch selbst in strengen elegischen Versen gehalten sind. Als wichtige neue Beobachtung ist hervorzuheben, dals das Schema hier trotz grofser Hindernisse und unter Beeinträchtigung der Schönheit der Verse durchgeführt ist. Damit ist einerseits bewiesen, dafs als das Entscheidende und Charakteristische an dieser Versart nicht eine bestimmte Länge der Glieder, nach Worten, Hebungen, Silben abgezählt, erschien, sondern das Verhältnifs des ersten Gliedes zum zweiten, das Ueberwiegen desselben, die Geltung des zweiten als eines kürzeren Nachhalls. Sodann aber lälst sich daraus schliel'sen, wie wichtig dem Propheten die Anwendung dieser Versform für das beabsichtigte Klagelied erschien, wie wenig er desselben dabei meinte entrathen zu können.

Dennoch hat Ezechiel sich in der Folge nicht mehr so lästigen Zwang auferlegt. Die Auflockerung der Versform, die wir in c. 27 beobachteten, ist die Ueberleitung zu nur ganz partieller Handhabung derselben in den folgenden gleichartigen Partieen. In dem folgenden Capitel bleibt Ezechiel im Ganżen in dem angestimmten Tone, die Einführung des Ausspruchs über den Fürsten von Tyrus ist zuletzt dasselbe : (1) כה אמר ארני יהוה קינה 27, 3 dicht vor den Anfangsworten der eigentlichen lesen. Als solche wird nun zwar der Abschnitt 28, $1 \mathrm{ff}$.

1) Anders 19,$1 ; 26,17$. 
nicht hingestellt, es fehlt ihm auch die wesentlichste Bedingung dafür, die Darstellung des Sturzes als eines bereits vollzogenen, als Todesfall empfundenen und beklagten; und dem entsprechend erweist es sich auch als Unmörolichkeit, das Stück nach unserem Schema abzutheilen. Dennoch darf es nicht verschwiegen werden, dals einige.Ab-

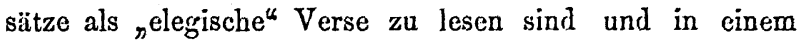
zusammenhängenden Klageliede nicht anders aufgefalst werden könnten. Man theile. vor allem nur 9a, b, 10* bei Zaqeph qaton und Tiphcha, um sich davon zu überzeugen, wenn man auch finden wird, dafs die Einschnitte sehr schwach sind. Ich meine die Erscheinung daraus erklären zu müssen, dals der Prophet die Stücke uno tenore schrieb und der Tonfall des Klageliedes ihm so im Ohre lag, dafs die Worte sich mehrfach zwanglos in ihn fügten. - Mit v. 11 f. aber wird ein neues Klagelied in gewohnter Weise angekündigt, das der Hauptbedingung, den Sturz als' vollzogen darzustellen, entspricht. Aber auch hier macht der Prophet zunächst gar keine Anstalten, in den Rhythmus des Klageliedes einzulenken, und vergebens wäre das Bemühen, mehr als leise Anklänge daran aufzuzeigen. Aber nicht bis zum.Schlufs. In v. 18 und 19 falst er noch einmal die Schuld und die Strafe des Königs von Tyrus zusammen, greift nun klar und fest den Rhythmus des Klageliedes auf und führt das Stück in 5 scharf geschnittenen Versen zu Ende. Damit gar kein Zweifel bleibe, lautet der letzte Vers ebenso wie der Schlufsvers von cap. 27.

Noch einen Schritt weiter geht die Auflösung in dem letzten Stücke, welçhes als קינה angekündigt wird, in 32, 1-16. Auch die Fiction des eingetretenen Todes ist hier aufgegeben ${ }^{1}$ ), und was den Vers anbetrifft, so ist fast

1). Schon in den ersten Worten, die ja auf das wirklich bereits Geschehene gehen, nicht erst in v. 3. (Smend.) 
durchweg ein ganz anderer, gleichschwebender, meist zweigliedriger Vers mit auffallender Genauigkeit eingehalten ${ }^{\mathbf{1}}$ ). Aber auch hier steht es anders mit dem Schlufs. Von v. 12 an tritt nach einem kurzen Vorschlag der Vers des Klageliedes ein. Die ersten drei Verse wird man leicht erkennen (Trennung bei dem Zaqeph qaton), der vierte, 13", könnte Zweifel erregen, doch spricht für Streichung

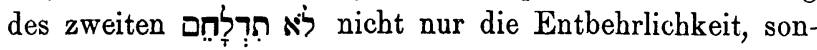
dern auch die singularische Form. In der Peschítâ fehlen diese Worte. Vers 14 will wieder nicht stimmen, v. 15 läfst sich nicht ohne Schwierigkeit in zwei richtige Verse theilen (Verstheiler Zaqeph, Cäsur bei Rebia und_Athnach), und bei beiden wage ich nicht zu behaupten, dals es früher besser damit gestanden habe. - So verläuft dieses letzte Klagelied in jeder Beziehung im Sande, wie in der Haltung und Ausprägung des Gedankens, so auch in der dichterischen Form, und es gehört allerdings eine so nachdrückliche Versicherung, wie Ezechiel sie in v. 16 gibt, dazu, uns glauben zu machen, dafs wir es wirklich mit einem Klageliede zu thun haben.

Als letztes, bei dem nun folgenden Stücke v. 17-32, das Ewald und Smend unnöthigerweise als Grablied von dem Trauerlied unterscheiden ${ }^{2}$ ), schwindet auch die gewohnte Einleitungsformel, das שא קינה ואמרת, und ein blofses נחה nimmt die Stelle ein. Dennoch flackert auch in diesem Stücke gelegentlich noch der begrabene und verschüttete Rhythmus auf in dem סביבותיו קברתיו (v. 22, und nur in dem Suffix verschieden v. 24, 25, 26), das jedesmal mit der vorhergehenden Aufzählung einen elegischen Vers

1) Vgl. besonders v. 4. 5. 7. 8. Kein einziger Vers läfst unser Schema zu.

$\left.{ }^{2}\right)$ In Wirklichkeit könnte es dem Inbalte nach nur allenfalls die קינה sein, die v. 1-26 nicht ist. 
bilden könnte und in seiner dumpfen Wiederbolung an (ihnliches in cap. 27 anklingt ').

Wir können also bei Ezechiel, der überhaupt in der hebräischen Prophetie die allmähliche Auflösung ihres Bundes mit der Poesie einleitet, in auffallender Stetigkeit durch vier aufeinander folgende Stücke hindurch auch die allmähliche Auflösung der Form des Klageliedes verfolgen. Und doch lebt sie später in Jes. 14 nicht, wie Ewald behauptet, an dem Vorbild von Ez. 19 oder auch 32, 1-16, sondern gerade an dem fast formlosen Stück Ez. 32, $17 \mathrm{ff}$. wieder auf, ein Beweis, wie wenig der Verfasser für die Form eines Lehrmeisters bedurfte.

Wenn wir nun ferner sehen, wie bei Ezechiel keine anderen Stücke als nur eben diese, mit קינה bezeichneten, diese Versform aufweisen ${ }^{2}$ ), wenn wir sie dagegen von ihm gleichzeitig mit der Abfassung des Buches der Klagelieder in typisch festem Gebrauch eben hierfür finden : so ist damit der Beweis erbracht, dafs er diese Form für das Klagelied als längst überliefert vorfand und darauf rechnen durfte, durch diese gewohnten Klänge besonders tiefen Findruck hervorzurufen. Dafs dies kein Irrthum ist, soll zunächst aus einigen Stücken des Propheten Jeremia bewiesen werden.

Das Wort pindet sich bei ihm 3 mal, 7, 29; 9, 9.19. In der ersten Stelle wird der Aufforderung, ein Klagelied anzustimmen, in Worten keine Folge gegeben, sie ist an Zion gerichtet, Gott aber fährt sogleich in der Rede fort. In cap. 9, 9 dagegen heilst es : „Ueber die Berge will ich Weinen und Weheruf (נהי) erheben, und über die Auen der Steppe ein Klagelied : dals sie verbrannt sind, von Niemand durchwandert, und keiner Heerde Stimme vernehmen." Und nun wird man in dem folgenden Abschnitt

1) S. übrigens über נה weiter unten.

$\left.{ }^{2}\right)$ So ist gleich die חירד in cap. 17 ganz anders gebaut. 
bis zu Ende von v. 10 den Rhythmus des Klageliedes deutlich erkennen. In nur 3 klaren Versen nach unserem Schema wird die Rede Jahve's zu Fnde geführt ${ }^{1}$ ), bis in v. 11 die Frage eingeworfen wird, wer denn den Rathschlufs Jahve's verstehe. - Viel charakteristischer aber und umfangreicher ist das folgende Stück, von v. 16 an : „So spricht Jahve Zebaoth : Merket auf und rufet die Klageweiber (טקוננות), dals sie kommen, und zu den weisen Frauen (חכמוח) sendet, dafs sie kommen : dafs sie eilends erheben über uns den Weheruf, und unsere Augen rinnen von Thränen und unsere Wimpern triefen von Wasser." Man erkennt deutlich gleichschwebenden Rhythmus. Aber als wenn inzwischen nach einer Pause die Weiber gekommen, so heben nun die gebrochenen Rhythmen des Klageliedes an, sogleich auch im Beginn des zweiten Gliedes das und die Klage ergielst sich in zwei solchen Versen in v. 18. Dann bricht sie ab, und in gleichschwebenden Versgliedern ergeht eine neue Aufforderung (v. 19) : „Denn höret, ihr Weiber, das Wort Jahve's, und euer Ohr nehme auf das Wort seines Mundes; und lehret eure Töchter den Weheruf, und eine die andere das Klagelied (קינה)." Und nun folgt ein echtes Klagelied in den gewohnten Versen, deren 4 bis zu Ende von v. 21 folgen, um dann ganz scharf wieder gewöhnlichem Tonfall Platz zu machen. Das zu Anfang von v. 21 ist mit LXX (Ew., G raf) zu streichen. Es ist Glosse zu v. 19 und will darauf aufmerksam machen, dafs v. 20 f. eben das Klagelied enthalten, ist also obendrein an die falsche Stelle gerathen. Das zu Anfang von v. 18 und 20 ist nicht zu übersetzen, vielmehr blofse Einführung der citirten directen Rede (cf. Ges. Thes. sub B. b.) ${ }^{2}$ ).

1) Anfang mit פעy, die Cäsuren der 3 Verso sind richtig mit Zaqeph und Tiphcha bezeichnet.

2) Zweifelhaft könnte dies nur für v. 18 erscheinen, wenn man dort die directe Rede erst mit dem איך beginnt; doch setzt der Rhythmus schon mit Anfang des Verses ein. 
Die Stelle ist durchschlagend, wir müssen deshalb hier einen Augenblick innehalten, um aus ihr die unabweisbaren Folgcrungen zu zichen. Im ganzen A. T. wird an dieser einzigen Stelle jenes hochwichtigen Pestandtheiles aus dem Apparat des feierlichen Leichenbegängnisses, der Klage-

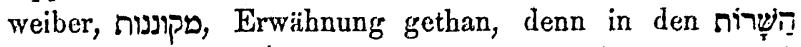
neben den כל כל II. Chr. 35, 25 haben wir es.mit einer starken Verallgemeinerung zu thun. An unserer Stelle erscheinen sie durchaus als Klageweiber von Profession, die herbeigerufen werden, wo nan sie nöthig hat, um eilends die קינה anzustimmen; nicht sind es die Weiber der Familie, des Ortes, die vorkommenden Falles dieses Geschäft übernehmen. In Parallele zu dem "מקונ steht der Ausdruck die weisen Frauen", auch nur hier im A. T. zu finden (anders Jud. 5, 29). Diese Bezeichnung giebt eine sichere Gewähr dafür, dafs' es sich bei ihrem Amte nicht blofs um gewohnheitsmälsig handwerksmälsiges Gebahren, schmutzigen, zerlumpten Aufzug, Schmerzensgesten, Heulen, Ausrufe handelt, sondern um eine wirkliche Kunst, und in der קינה um ein wirklich gesungenes Lied mit - vernünftigem, in Worten niedergelegtem Inhalt, dichterischer Form und musikalischer Composition. Das wird ferner bestätigt durch die Aufforderung in v. 19. Die Weiber sollen horchen auf das Wort Jahve's durch des Propheten Mund und dann die קינד einander gegenseitig und jede ihre Töchter lehren, die in den folgenden Versen gegeben wird. Es ist also ein neues, kunstrolles Klagelied, was sie den alten, die sie bereits können, hinzufügen und weiter verbreiten und vererben sollen; sie haben Ursache aufzuhorchen, wo dergleichen zu hören ist. Ist aber die dichterische Form dieses Stückes dieselbe wie desjenigen in v. 18, das höchst wahrscheinlich den Klageweibern selbst in den Mund gelegt ist; finden wir ferner, wo immer eine קינה citirt wird, diesen selben Rhythmus wieder, so ist dies eben der feststehende Rhythmus der eigentlichen קינה, be- 
gründet auf eine stehende Melodie, die ihm in einer längeren und einer nachfolgenden kürzeren musikulischen Phrase genau entsprach. Das ist ein sicherer Schlufs, mögen wir auch über die Art der Musik gar nichts aussagen können. Nur der Umstand, dafs es für die kunstvolle Leichenklage eine solche stehende Melodie gab, und dals diese Melodie auch den Text in so charakteristische Rhythmen zwang, lälst es begreifen, wie die Propheten, wenn sie mit ihren Klagen einen recht tiefen Eindruck machen wollten, sogleich in diese Versform übergehen. Weckten sie doch mit diesem Tonfall in den Herzen aller Hörer die Erinnerung an ernste Tage und Stunden, in denen sie um die Leichen ihrer Angehörigen standen und mit trauerten und klagten.

Für die hier vertretene, mir vor jeder Vergleichung unzweifelhaft gewordene Auffassung fand ich in vielen Stücken eine höchst willkommene Bestätigung aus dem frischen Leben der heutigen Orientalen in einem auch sonst ungemein inhaltreichen und wichtigen Aufsatze von Wetzstein ${ }^{1}$ ). Während sonst der Ritus der Leichenklage, von dem Koran ungern gesehen, bei den verschiedensten orientalischen Stämmen immer mehr in Verfall geräth und insbesondere die lautlichen Aeufserungen meist nur noch in inartikulirten Tönen oder kurzen Rufen und Formeln bestehen, hat hierin wie in vielen anderen Dingen (vgl. Wetzstein's Excurse zu den Commentaren von Delitzsch) Syrien in der Umgegend von Damaskus, Dscholân, Haurân u. s. w. alte Sitte treu bewahrt, sodals

1) „Die syrische Dreschtafel" in Bastian's Zeitschrift für Ethnologie 1873. S. 270 ff., 5) „Die Tafel als Paradebett" S. 294 ff. Die Nachweisung des Aufsatzes, der leider an so entlegener Stelle erschienen ist, und vor allem mit einem Titel, unter dem nicht leicht Jemand dergleichen suchen wird, verdanke ich der Güte Gildemeister's. 
viclfache unmittclbare Uebereinstinmung mit dem Alten 'T'estament sich nachweisen läfst. Dort ist bei Juden, Mrshatnmedanern und Christen aller Schattirungen in Stadt, Dorf und Zelt, eine im ganzen identische, sehr umstaindliche Leichenklage in Gebrauch, aus deren Beschreibung ich das für unseren Zweck Wichtige heraushebe.

Die vollstïndige Leichenklage dauert 7 . Tage und wird tiiglich mindestens einige Stunden von den dazu bestimmten Weibern erhoben. In den Stälten, vor-allem in Damaskus, giebt es einen vollständigen, zunftmülsig geschulten Weiberchor, die latțâmât, , die sich ins Antlitz schlagren", denen der Chor der weiblichen Verwandten u. s. w. respondirt. An Stelle dieses ganzen geschulten Chores, von dem abwechselnd eine die Vorsängerin zu machen pflegt, tritt auf dem Lande eine berufsmäfsige Solosängerin, die kauwâla, „die Sprecherin, Dichterin", selten von einer oder zwei anderen unterstützt. Sie ; muls eine gebildete Stimme, einen reichen Vorrath von Nänien und ein gutes Gedächtnifs haben, damit sie sich nicht aufällig wiederholt, was bei einer vollständigen, also siebentägigen Klage nichts Leichtes ist, wenn diese auch des Tags auf $2^{1 / 2}$ Stunden beschränkt wird. Doch fehlt es im Lande nicht an solchen Sängerinnen, weil ihr Beruf sehr einträglich ist. Die Nänie, ..., welche immer die poetische Form, Metrum und Reim haben mufs, besteht meistens aus einem Doppelvers, doch auch aus 3 und 4 Verszeilen und ist - abgesehen von ihrem oft grölseren, oft (besonders wenn es Stegreifverse) geringeren poetischen Werthe - dem Sinne nach etwas Abgeschlossenes, ein fertiges Bild. Nach jeder Nänie erhebt der Chor den Weheruf. Dasselbe "geschieht, wenn das Klagelied aus einer längeren Ode bestehen sollte, nach jeder einzelnen Strophe. Zum Chore gehören sämmtliche Frauen, welche den Ring um das Zelt bilden; sie heifsen reddâdât „die Respondirenden" oder neddâbât und nauwâhât „die Klagefrauen“. Der Weheruf, in Syrien wélwěla, 
an der Küste hin und wieder wilwâl genannt, besteht aus dem blolsen Wörtchen wêlî, wehe mir!"

Ich habe bis hierhin Wetzste in selbst reden lassen, weil fast jedes Wort dieses Abschnittes für unseren Gegenstand bedeutsam ist, derart, dal's ich kaum erst auf das Einzelne kinzuweisen brauche. Nichts steht dem im Wege, dafs die Leichenklage zu Jerusalem vor $2 \frac{1}{2}$ Jahrtausenden im wesentlichen ebenso gehandhabt wurde, wie jetzt und wohl schon damals in Damaskus; die Religionsverschiedenheit wird auch damals in solchen allgemein menschlichen Dingen keinen Unterschied begründet haben. Die Unterscheidung der ķauwâla von den Respondirenden entspricht ganz der Bezeichnung der „weisen Frauen“. bei Jeremia, deren in Jerusalem wohl auch ein ganzer Chor vorausgesetzt werden darf wie in Damaskus ${ }^{1}$ ). Dichterische Form und Melodie hier wie dort; ein Vorrath an Liedern, der im Gedächtnifs gehalten wird und der Vermehrung fähig ist, schwerlich auch alle eigenes Product der Sprecherin, gerade wie Jer. 9, 19 ff. Dazu die Weherufe, wie sie uns ebenso im A. T. begegnen, so Jer. 22, 18 (I. Kön. 13, 30), vgl. dazu Wetzstein S. 298, Jer. 34, 5. Die angegebene Länge des einzelnen Klageliedes, 2-4 Verszeilen, stimmt sehr gut zu den kurzen Stückchen in Jer. 9, Ez. 26, $17 \mathrm{f}$. und manchen anderen, die noch anzuführen sind. Auch für die längeren zusammenhängenden Stücke finden sich Analogieen. Was Wetzstein von dem sinneberauschenden, grauenhaften dramatischen Apparat und der erschütternden Wirkung besonders der städtischen Leichenklage zu berichten weifs, harmonirt vortrefflich mit der Wirkung, die Jer. 9, 17 von dem Gesang der weisen Franen erwartet, und in zweiter Linie mit der Wirkung, die sich

1) Doch brauchen darum die מקיננות keineswegs im Unterschiede davon den nicht zunftmälsigen Chor der reddûdât zu bezeichnen. 
die Propheten von der Anwendung dieser Rhythmen müssen versprochen haben. Die Ableitun: des Wortes die Wotzstcin gicbt, verdient alle Beachtung; er führt es auf die Stammesbedentung „künstlich bilden, zusammenfügen" zurück und lïlst die Wahl, ,ob es von der pretischen Form oder (wahrscheinlicher) von dem den Todten ausschmückenden Inhalt" benannt ist. Auf Grund des Ausgeführten möchte ich für das erstere eintreten und vor allem datauf aufmerksam machen, dals-קינה und nur von wirklichen Klageliedern, von Kunstproducten vorkommen (was auch Ez. 2, 10 am nächsten liegt), während נהי (נהוה), wenn es auch in Jer. 9, 9. 19 die Parallele zu

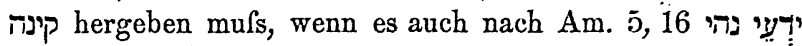
giebt (vgl., was W. über die Kunstfertigkeit beim Weheruf S. 297 sagt), doch schwerlich den kunstvollen Klagegesang bezeichnet : so sicher nicht in Jer. $31 ; 15$, wo die eigene Mutter ihre Kinder beweint, und noch weniger das Zeitwort in I. Sam. 7, 2, wo es am besten mit „seufzen" wiedergegeben wird (nicht sich versammeln ${ }^{\star}$ ). Die Denomination von einem blofsen Ausruf ist mir bei diesem Stamm überwiegend wahrscheinlich, und damit fände der i seine Parallele an der wélwĕla der syrischen Leichenklage $^{1}$ ).

Das Einzige, worin Wetzstein's Nachrichten und die angeführten Bëspiele von Klageliedern mit unseren Beobachtungen nicht übereinstimmen, das sind die angewandten poetischen Formen, die Metra der Lieder. Nur eine höchst unhistorische Vermessenheit hätte das anders

1) Ges. Thes. erklärt es : clamavit $\boldsymbol{F}_{T} \boldsymbol{T}_{\text {, }}$, was nicht wahrscheinlich. Vielleicht ist es ursprünglich Niphalbildung zu dem Aus-

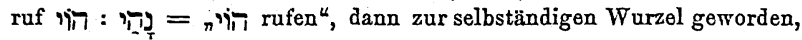
von der das Nomen בִּ und sugar ein neues Niphal (I. Sam. 7, 2) gebildet wurde. 
erwarten können. Wie bei aller Volkspoesie, so hat sich auch hier, bei gröfsester Zähigkeit der alten Sitte, der stetig sich gleich gebliebene Inhalt in die mit der Zeit ebenso stetig fortschreitenden und wechselnden Formen der jedesmaligen Gegenwart umgegossen : hier in die gewöhnlichen Metra und gereimten Strophen der arabischen Poesie ${ }^{1}$ ). Dals vor $2^{1 / 2}$ Jahrtausenden auch in Damaskus der im alten Testamente nachgewiesene Klageliedvers gesungen wurde, kann man allenfalls vermuthen : dafs sich heute keine Spur davon mehr finden kann, darf man mit weit gröfserer Sicherheit behaupten.

Nachdem so, wie ich glaube, die nachgewiesenen Erscheinungen ausreichende Erklärung, meine däraus gezogenen Schlüsse hinreichende Begründung erhalten, fahre ich in der Aufführung der im alten Testament vorhandenen Stücke in Klageliedform fort. Bei dem Propheten Jeremia selbșt finden sich noch einige weitere, und zwar, wie nicht anders zu erwarten, in cap. 22, wo Jeremia mit wahrer eigener Herzenstrauer über die Könige von Juda klagt. Hier steigern sich, wenn auch ohne Nennung der קינה, ohne dafs es sich um wirklich Todte handelte, doch einige Stellen bis zur Kunstform des Klageliedes. Es sind das 4 Verse in v. 6. 7., mit פְ̣ beginnend, durch die bekannten Accente richtig abgetheilt. Sodann 6 Verse in. v. 21—23. In v. 21" ist das ' mit LXX zu streichen, in $22^{\mathrm{a}}$ ist das zweite Glied etwas lang, in $23^{\mathrm{a}}$ die beiden Glieder gleich lang. Da diese 2 nicht regelrechten Verse von 4 anderen umschlossen werden, so wage ich es dennoch, das Stück als mit Absicht klageliedähnlich zu be-

1) Die deutsche Literaturgeschichte liefert dafür die schlagendsten Belege, aber auch die späteren Juden haben ihre alte poetische Form verlassen und vergessen und sich der arabischen Poetik gefügt. Wio früh ihnen jene abhanden gekommen ist, beweisen die vielfachen Textverderbnisse, die uns hier begegnin. 
tracliten. In beiden Stücken macht es einen besonderen, wehmüthig schünen Eindruck, wie Jahve gleichsam dem Konigshause und /ion die Klage abnimmt und selbst seine Strafankündigung in sie einkleidet. Ich betone aber ausdrücklich, dafs hier das Klagelied in eine rhetorische Form ałsgelaufen ist, fast unwillkürlich angewandt, ganz anders als in cap. 9. - Gelegentliche Ankliinge finden sich auch in v. 10 und $13 \mathrm{f}$, aber sic widerstreben dem Versnche ein Stiick geordnet abzugrenzen.

Weitere Stücke habe ich bei Jeremia nicht gefunden.

Klagelieder kündigt mit dem Worte קינה an auch Amos. In cap. 5, 1 heilst es : „Höret das Wort, das ich als Klagelied über euch anhebe, Haus Israels :

Gefallon ist, stehet nicht wieder auf

Die Jungfrau Israel.

Auf ihren Boden ist sie hingeworfen,

Keiner hebt sie auf."

Zwei Verse genau nach unserem Schema, und das Lied ist zu Ende. - In cap. 8, 10 ist die Ankündigung finsterer Trauerzeit selbst in das Gewand des Klageliedes gekleidet, als wenn mit dem Worte קינה das Klagelied selbst heraufkäme. In v. 9 heifst es : „Und an jenem Tage, spricht der Herr Jahve,

Lasse ich die Sonne niedergehen am Mittag

Und verfinstere die Erde am bellen Tage

10) Und ich verwandle eure Feste in Trauer

Und all eure Lieder zum Klagelied

Und bringe über alle Hüften das Trauergewand

Und auf jedes Haupt eine Glatze

Und versetze sie wie in Trauer um den einzigen Sohn,

Mache ihr Ende wie einen herben Tag." .

Es läfst sich schwerlich verkennen, wie v. 9 noch völlig in gleichschwebenden Gliedern sich ergeht, die auch logisch sich die Wage halten, und wie dann mit v. 10 der Rhythmus des Klageliedes eintritt und jedes erste Glied das 
Prädicat für das zweite mit erhält ${ }^{1}$ ). In nur 3 Versen hat sich der Ton des Klageliedes erschöpft.

Endlich mit dem Worte נרי führt die directe Rede eines Klageliedes ein Micha in cap. 2, 4. Fs ist das die einzige Stelle, wo eine Klage angestimmt wird, ohne dals ich behaupten dürfte, dals auch hier der Prophet jenen Rhythmus angewendet habe, oder, wenn ich dabei bleibe: welches die Grenzen dieser Anwendung seien. Das Klagelied sollte eigentlich beginnen mit seinem ersten Ausruf נריזיה, der durch das eingeschobene אמר als directe Rede angekündig't wird. Aber $4^{\mathrm{a}}$, die Einführung des Liedfragmentes, liefse sich auch, sogut das auf Zufall beruhen kann, als ein elegischer Vers bei dem Rebia theilen, und man könnte sich dafür auf Am. 8,10 berufen. In $4^{\mathrm{b}} \mathrm{mufs}$ man fragen, ob das eingeschobene אמר mit in den Rhythmus gehört - dann wird mit der Anführung des Klageliedes selbst kein rechter Ernst gemacht; oder ob es nicht mitgerechnet ist - dann bleibt zwar das Uebergewicht des ersten Gliedes noch ausreichend gewahrt, aber der Eindruck des Stückchens ist schwer geschädigt. Endlich $4^{c}$ lälst sich, da in einem Stückchen von 2-3 Versen die oben gesetzte Licenz Nr. 3) nicht in Betracht kommen kann, als elegischer Vers schlechterdings nicht begreifen, und eine Umstellung, wodurch allerdings ein regelrechter Vers entstünde, wage ich nicht zu vertheidigen. Nehme ich an, dafs der Text ganz in der ursprünglichen Fassung vorliegt, so mufs ich zugeben, dafs der Prophet eine Anwendung unseres strengen Schema nicht beabsichtigt hat, und das dann daraus erklären, dals משל, das allgemeinere Wort, voransteht, נהי, wie oben ausgeführt, ein kunstmälsiges Klagelied wohl nicht bezeichnet : dafs der Dichter deshalb

1) Nur scheinbar in $\checkmark .10 \mathrm{c}$ anders, wozu die Uebersetzung von שim im ersten Gliede zwang. 10c ist wohl nach Nr. 2) zu erklären. 
in der gewohnlichen Rede verblieben ist und den Klageton scharf genug durch die Rufe אִ glaubte markirt za haben!).

Und nun will ich von der Schwelle des prophetischen Schriftthums aus, wohin uns die Amos-Stellen geführt haben, allmählich hinabschreitend, die Stellen aufführen, an denen ohne Kundgebung der Absicht der Rhythmus des Klageliedes in zusammenhängenden Stücken sich findet; es wird sich daraus ergeben, was gewifs nicht mehr überraschen kann, dals für den Propheten, den vorzugsweise klagenden, elegischen Volksredner, dieser Tonfall ein vor andern beliebtes Mittel war, Stimmung bei dem Volke zu erwecken.

So ist in Hosen 6,7ff. die Klage Gottes über die Treulosigkeit und Verderbtheit seines Volkes in die Form eines eigentlichen Klageliedes gegossen. Nur die Darstellung dieses Zustandes hat'diese Form, das Vorhergehende nicht. Der Text ist von dem Masorethen mehrfach falsch abgetheilt; Aenderungen, die auch durch den Sinn geboten und theilweise schon vorgeschlagen sind, werden durch die Beobachtung des Rhythmus bestätigt. Vers 7 und 8 sind klar. In v. .9, ist der Schlufs des ersten Verses bei כדזנים, die Cäsur bei גדורים zu setzen, nicht über das Zaqeph hinweg bis zum Athnach fortzulesen ${ }^{2}$ ). Es ergeben sich dann 2 regelmäfsige Verse, auch der Sinn gewinnt. Vers 10 ist mit לאפרים zu schliefsen (Verstheiler Athnach); das נטמא ישראל ist zù v. 11 zu ziehen, und das נם יהודה in v. 11 ist zweites Subject zu נשמא, wodurch Schwierigkeiten beseitigt werden. In dem kürzeren Halbvers שיר קציר לך

1) Zufällig sind wohl Anklänge an den Rhythmus des Klageliedes in $1,6 .-14 ; 2,2$.

2) Aus Nowack Hosea ersehe ich, dafs auch Wünsche so theilt. Er hat hier Recht, die. Bedenken N.'s dürften schon durch Stellen wie Jes. 10,$9 ; 29,7$ beseitigt sein und sind gewifs nicht grofs. 
wendet sich Gott in theilnehmender Anrede zu der neuen Person Juda hin, im Uebrigen wird sich Ewald's Auffassung von py und dem ganzen Halbvers empfeblen. Die letzten Worte ב'שובי שבות עמי hat schon E w ald richtig zu cap. 7 gezogen, der Rhythmus bestätigt dies, indem sie nun mit den zwei ersten Worten von cap. 7 einen regelrechten Vers ausmachen und zwei weitere in v. 1 übrig lassen. (Haupttheiler das erste Zaqeph, Cäsuren bei dem Paschta und zweiten Zaqeph). Vers 2 enthält zwei, v. 3 einen richtig geschnittenen Vers, mit v. 4 bricht der Rhythmus ab. Es liegt also hier ein Stück von 12 tadellosen Versen vor, bei dem Zufall ausgeschlossen ist. Dafs der Gegenstand für weitere Uebertragung des Klägeliedes ein sehr geeigneter ist, wird man nicht, leugnen können.

Bיכה des Klageliedes, und mit ihm stellen sich zwei Klageliedverse nach unserem Schema ein. In $21 \mathrm{~b}$ ist deutlich der stärkere Einschnitt nach iฺฺ, und das erste Glied nach Nr. 1 in Ordnung. - In 22, 3. 4 liegen sicher vier Klageliedverse vor; der Form und dem Inhalt nach könnten sie dem Buche der Klagelieder selbst angehören. Vers 1 und 2 dagegen würde man nur mit Mühe und nicht fehlerlos nach dem Schema lesen können; doch mufs ich, namentlich auch der Sprache und des Zusammenhangs wegen, vermuthen, dafs v. 3 und 4 in späterer Zeit wegen der klageliedähnlichen Haltung von v. 1. 2 hier eingeschoben sind, was hier nicht weiter ausgeführt werden kann. - In cap. 23 - die jesajanische Abfassung lasse ich hier dahingestellt gehört das Fragment aus dem Liede von der vergessenen Buhlerin hierher. Die Art der beiden Verse, die v. 16 bilden, ist wie 1, 21. b. Das Lied ist gewils ein spottendes Klagelied über die quasi-Leiche gewesen, und unser kleines Fragment schliefst alles eher in sich, als dafs der Buhlerin ihr Singen so gut helfen werde, wie Tyrus sein erneuter Handel. Es ist eben nur Hohn. Wir sehen also, 
dals auch der Volksmund sich des Klageliedes zu anderen Zwecken bemïchtigt hat.

Bei Obadja finden sich zwei kleine Stücke, die in unserem Rhythmus verlaufen; beide lösen sich. scharf aus der Umgebung los. Das zweite, v. 12-14, würde aus 8 Versen bestehen, deren zweites Glied mit einer Aus-

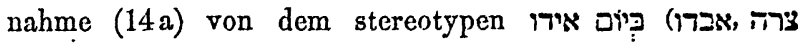
u. s. w.) gebildet wird. Es scheint hier die Annahme nicht ausgeschlossen, dafs ein formell gleicher Effect durch ein materiell ganz verschiedenes Motiv herbeigeführt ist; doch läfst der Gegenstand auch die Form des Klageliedes als beabsichtigt zu. - Dagegen ist das erste Stück, v. 6. 7, ein aus 4 Versen bestehendes, nach Inhalt und Form ur sprüngliches, mit dem charakteristischen $\underset{i}{ } \mathbf{i}$ eingeleitetes Klageliedchen ${ }^{1}$ ). Dafs auch aus diesem Zusammenhange unter Zerstörung des rhythmischen Baues Stücke in Jer. 49 sich wiederfinden, dürfte-als ein neues Moment für die wesentliche Priorität von Obadja zu betrachten sein ${ }^{2}$ ).

Weiter darf ich nicht übergehen ein Paar von Propheten, bei denen eine gewisse Abschwächung in dem Gebrauche unseres Schema zu spüren ist, es sind das Nahum und Zephanja. Beide gebrauchen das Schema nicht mehr so absichtlich, nicht in so specifisch geeigneten, noch in so scharf abgegrenzten Stücken, es fliefst ihnen mehr unwillkürlich mit ein. Man könnte diese Erșcheinung gegen den eigentlichen Kern dieser Abhandlung ins Feld führen, wenn nicht durch die grolse Zahl als Klagelieder ausdrücklich bezeichneter Stücke die Thatsache selbst, dafs dieses Schema das des wirklichen Klageliedes war, unerschütterlich feststände, und wenn nicht andererseits in den besprochenen prophetischen Stücken jeder Schritt, der weiter

1) In $7 \mathrm{a}$ das $\mathrm{gu}$ streichen?

$\left.{ }^{2}\right)$ Wofür ich mich auch in Jahrbb. f. deutsche Theol. 1878 S. 456 entschieden habe. 
von dem realen Vorbilde abführt, in so ununterbrochener Stufenfolge belegt werden könnte. Einen der am weitesten vorgeschobenen Posten nehmen eben die beiden zuletzt genannten Propheten ein, bei denen der elegische Tonfall öfter auftaucht und verschwindet. Ich will nicht unterlassen, die Hauptstellen zu erwähnen. - Im Buche Nahum lärst sich 2,1-3 in 7 erträgliche Verse (meist mit etwas gedehntem ersten Gliede) theilen, der Sinn ist ein dem Klagelied wenig adäquater, Strafandrohung für Assur mit gleichzeitiger Heilsverheilsung für Israel. Im einzelnen besteht v. 13 aus zwei ganz correcten Versen. Endlich scheint der Schlufs 3, 18. 19 in 5 Klageliedverse auszulaufen, der letzte allerdings mit künstlicher Cäsur, der vorletzte nicht scharf geschnitten. Der Sinn dem Klagelied wohl angemessen. - Dem Propheten Zephanja ist dieser Rhythmus noch mehr in Fleisch und Blut übergegangen. So in $1,4-5$, einzelne Verse hier und da. In 2,12 beginnt ein zusammenhängendes Stück, das mit Absicht so gehalten sein wird, die Verkündigung der Verwüstung Ninive's, in der dem Klagelied verwandte Klänge sehr häufig sind. Es sind 9 meist gute Verse; nur v. $14 \mathrm{c}$ will nicht recht stimmen, in dem Schlufsvers, 15d, ist der Vers bei dem Tiphcha zu theilen. Das Schlufscapitel endlich verläuft fast ganz in unserem Rhythmus, nur dafs er nachlässig gehandhabt ist, und immer wieder die Kette reifst. So gleich v. 2, nachdem v. 1 mit seinem הo schön den Ton angegeben und den Rhythmus scharf aufgegriffen hat. Stücke, die entschiedenere Haltung aufweisen, sind etwa v. 7-8, 13-16, und der Schlufs v. 19-20. Ich muls, um nicht unvorsichtig zu erscheinen, in solchen Stücken die Wahl freigeben, ob Zephanja das Schema gewollt und nur nachlässig angewandt hat, oder ob sich ihm unwillkürlich die Rede meistens so ergols. Zu seiner finsteren, dumpfen Art pafst jedenfalls der Ton des Klageliedes besonders gut. 
Endlich noch das Buch Deutero-Jesaja. In seiner enarratio metrica des Jesaja gibt Gietmann für cap. $\left.45,14-25^{1}\right)$ und cap. 47 den versus hendecasyllabus an, worunter er den Vers von Thr. 1-4 und Jes. 14, $4 \mathrm{ff}$. versteht. Nur zum Theil hat sich mir diese Berbachtung bestätigt, zunächst insofern, als sich hier allerdings und, soweit auch ich sehen kann, nirgend anderwärts in dem sonst der Form nach ziemlich gleichmülsig gehaltenen Buche der betreffende Vers vorfindet. - Aber auch nur mit einiger Regelmälsigkeit durchgeführt ist der Vers in dem ersten Stücke nicht. In c. 45, 14-25 sind es im Grunde nur wenige Verse, die eine sichere Theilung nach unserem Schema gewähren, v. 17 mit zwei, v. 25 mit einem Verse, daneben nur einzelne Theile der masorethischen Verse, während das Gleichgewicht durch andere Rhythmen sogleich wieder gestört" wird. Von bèwufster Anwendung der Form des Klageliedes kann demnach hier keine Rede sein, wie denn auch der Inhalt in keiner Weise dazu auffordert. Anders steht es mit cap. 47. $\mathrm{Da}$ klingt uns in v. 1 in der Anrede an die Jungfrau, Tochter Babel, sogleich das Klagelied entgegen, und wir werden, wenn auch hier spottweise, lebhaft erinnert an die Klage um Jerusalem in dem Buche der Klagelieder, daneben an die Klagelieder Ezechiels. Aber wie bei den späteren Stücken dieses Propheten, so ist auch hier die Form nicht ängstlich gewahrt, sondern bricht nur an den Hauptstellen, von dem Inhalt fast unwillkürlich geschaffen, hindurch. So besteht v. 1 aus 3, v. 5, ganz gleichen Inhälts, aus 2 Klageliedversen; v. 8 bietet 3 schon weniger scharf geschnittene Verse; v. 10 f. 6 ziemlich gute, und v. 14 falst zum Schlufs den Rhythmus energisch auf und läfst das Klagelied in 5 guten Versen ausklingen. Dazwischen scheint es hie

1) So S. 25 , S. 61 der Druckfehler : 46 . 
und da, als wenn wir es nur mit verwischten, verschwimmenden Klageliedrhythmen zu thun hätten, dann wieder treten ganz andere Rhythmen ein.

Die Thatsache, dafs nur hier im Buche des Deuterojesaja die Form des Klageliedes sich findet, steht in schönster Congruenz mit der anderen, dals dieses Stück auch dem Inhalte nach in dem ganzen Buche das einzige Klagelied genannt werden kann und in der Stimmung wie in dem Verhältnifs des Propheten zu dem Gegenstand seiner Rede von allen anderen sich scharf abhebt ${ }^{1}$ ).

Soweit meine Beobachtungen in den prophetischen Büchern. Dals sich gelegentlich dazu noch ein Nachtrag wird liefern lassen, wage ich nicht zu bezweifeln ${ }^{-}$doch ist, hoffe ich, mit obiger Aufzählung annähernde Vollständigkeit, wie beabsichtigt, so auch erreicht.

Ich schliefse die Reihe mit dem einzigen Stücke aus dem Buche der Psalmen, das sich völlig ebenbürtig jenen zur Seite stellt. Ein eigentliches Klagelied auf den Tod eines Menschen findet sich in dieser Sammlung subjectivlyrischer Gedichte nicht. Zur übertragenen Anwendung des Klageliedes gehören folgende Bedingungen, die in den oben angeführten prophetischen Abschnitten, soweit sie sicher erkannt werden können, mit ganz unwesentlichen Ausnahmen, erfüllt sind : 1) Ein unwiderruflich abgeschlossenes, irreparables Geschehen, auf das . nur rückwärts geblickt wird, während der Blick in die Zukunft im wesentlichen ausgeschlossen ist, 2) was damit gegeben ist : scharfe Unterscheidung des Klagenden von dem Objecte seiner Klage. Dem entsprechen weder die persönlichen Klagepsalmen, in denen die zweite Bedingung, noch die nationalen, in denen die erste regelmäfsig verletzt wird, da sie alle den Blick in die Zukunft richten, keine gleichsam liturgische

') Man wird hiergegen cap. 53 unmöglich anführen köunen. 
Haltung haben. Aber ein Psalm schlägt mit Bewufstsein in dramatischem Interesse den Ton des Klageliedes an, das ist Ps. 137. Ein frohes Lied fordern die Gewalthaber, aber nur Leichenklage um Zion tönen SIund und Saiten, und so erklingt die Antwort der Gefangenen sogleich in Gestalt eines Klageliedes um Jerusalem, in dem dieSchreckensbilder des יום ירושלם wieder heraufsteigen. Und wie es ausgeklungen, da richtet sich der Blick wieder zurück auf die Unterdrücker und die Gegenwart, und ein Fluch gegen Babel schliefst das Stück. Mit איך beginnt die Antwort der Gefangenen in v. 4, damit auch tritt das Schema des Klageliedes fest und sicher ein, bis zum 8 . Verse hin, wo die Anrede בת־בל wieder auf die Gegenwart hinlenkt. In 6 ganz unbezweifelbaren Klageliedversen hebt sich so der Kern des Psalmes von Einleitung und Schlufs ab, ein schlagendes Beispiel von dem specifischen Charakter, der dieser Versform beiwohnie.

Aber es gilt nun auch die Ausnahmen ins Auge zu fassen; die Fälle, in denen die Form des Klageliedes sich findet, ohne dafs ihr der Stoff entspräche, und weiterhin etwaige Klagelieder, die doch die hergebrachte Form nicht aufweisen:

Stücke der ersteren Art finden sich in dem Buche der Psalmen nicht selten, wie schon von Anderen bemerkt worden. So constatirt Ewald den „Langvers", De-

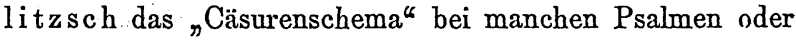
Theilen derselben : umfassendere Beobachtungen der Art finden sich bei Gietmann und besonders bei Ley. Wenn der letztere für diese Stïcke einen besonderen Vers, den Dekameter; im Unterschied von seinem elegischen Pentameter, annimmt, so-sind formelle Gründe, die hier allein entscheiden können, dafür nicht beizubringen, wie denn auch keineswegs jedesmal Verspaare, dem Ley'schen Dekameter entsprechend, sich in jenen Psalmen zusammen- 
schliefsen lassen ${ }^{1}$ ). Genauere Erkenntnifs des uns beschäftigenden Verses aber gebietet eine scharfe Sichtung der von Ley aufgeführten Psalmen, zumal dieser nicht weniger als 8 rhythmisch ganz verschieden wirkende Verse unter dem Begriff des Dekameters zusammenfalst.

Obenan mufs Ps. $42-43$ stehen ${ }^{2}$ ), weil bei ihm die Möglichkeit nicht abzuweisen ist, dafs der Dichter mit Bewufstsein die Form des Klageliedes als seinem Stoffe, dem eines persönlichen Klageliedes, entsprechend gewählt hat. Der Beweis für diese Möglichkeit liegt vor in Threni 3. Auch dort ist Subject und Object der Klage identisch, mischt sich die Hoffnung auf eine bessere Zukunft ein; andererseits zeigen uns 42, 5. 7; 43, 3 genügende Spuren auch objectiver Verluste. Das Stück ist weit überwiegend in Versen nach unserem Schema, aber mit sehr leichter Cäsur, geschrieben, der Kehrvers (v. 6. 12; 43, 5) besteht aus zwei Versen, deren zweitem noch ein drittes Glied (ישועות פני ואלהי) hinzugefügt ist ${ }^{3}$ ).

Die übrigen Stücke mögen nach: der Psalmzahl geordnet folgen. Grölsere Kürze empfiehlt sich bei diesem Appendix von selbst. Am leichtesten erkennbar und am allgemeinsten erkannt ist Ps. $19, v .8 f f$. Ueber die Frage, wieweit diese Versform reiche, herrscht grofse Meinungsverschiedenheit ${ }^{4}$ ). Meine Abtheilung stimmt bis v. 14 mit

1) Vgl. Ley S. 52 f. 45 ff., Gietmann S. 35 .

2) Erkannt von Ewald und Ley.

${ }^{8}$ ) Vers $1 \mathrm{a}$ (bis zum Athnach) stimmt nicht; in $1 \mathrm{~b}$ dio Cäsur beim Tiphcha. In $3 \mathrm{~b}$ die Cäsur beim Rebia. v. 5 gibt zu Bedenken Anlafs : ich würde versuchen, in a und b die Cäsur vor by und $\mathrm{zu}$ setzen. In v. 7 schliefst a mit v. 9 stimmt nicht. v. 11 a $\alpha$

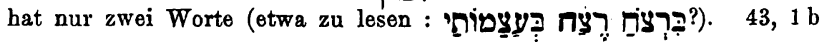
scheint unvollständig. In $4 \mathrm{a}$ ist das zweite Glied zu lang, in $4 \mathrm{~b}$ das erste Glied etwas kurz. Trotz dieser Bedenken glaube ich nach reiflicher Ueberlegung an beabsichtigte und ursprünglich vorhandene Regelmälsigkeit.

4) Schlimme Verwirrung stiftet hier Le y (S. 256 f.). Vgl. übrigens die bekannten Autoren. 
der von Delitzsch, ich crkenne bis dahin 12 klare Verse nach unserem Schema, nur $11 \mathrm{a}$ und $\mathrm{b}$ nach Nr. 2 zu erklïren. In v. 15 dagegen ist der Verstheiler nicht zu verlegen : ich sehe darin einen abschliefsenden Vers wie den Kehrvers 42, 6 u. s. w., gebildet durch Hinzufügung cines dritten Gliedes.

In 1 s. 27 scheinen v. 1-10 nach unserem Schema gebaut zu sein. Etwas schwierig $2 \mathrm{a}$ und 7 ; schwieriger v. 6, aus dem mit der Bickell'schen Vermuthung ירוה statt ליהוה drei wenig befriedigende Verse zu machen wären. Dagegen sind v. 8 und 9 dadurch herzustellen,

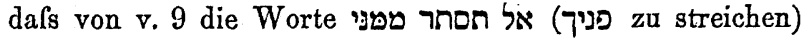
zu v. 8 gezogen werden. Es entstehen dann 4 gute Verse, und auch der Sinn gewinnt. Von v. 11 an tritt ein anderer Vers ein ${ }^{1}$,

In $P s .65$ hat Delitzsch richtig ein Stück nach unserem Schema abgegrerzt, die Verse 5-8, 5 Verse enthaltend und einen sechsten, v. 8, wiederum mit Hinzufügung eines kurzen dritten Gliedes. Wenn nun Giet m an n es fertig bringt, den ganzen Psalm nach dem versus hendecasyllabus abzutheilen (S. 108), so beweist er eben damit, dafs auch bei seinem System alles möglich ist. Die Verse, mit אשרי beginnend, heben sich in ihrem ruhigen Lob Gottes klar aus dem Zusammenhang heraus.

In $P$ s. 84 scheint zu Anfang ein zusammenhängendes Stück vorzuliegen. Vers 2 und 3 bieten drei gute Verse, v. 5 und 6 je einen. Vers 4 gibt zuerst einen guten Vers (zweites Glied וררור קן לרי); die zweite Hälfte des Verses ist dreigliederig : die richtige Lösung der Schwierigkeit nach Sinn und Metrum hat Ley gefunden (Stud. u. Krit. 1877, S. 508), indem er אשר שחה אפרחיה streicht und so einen zweiten guten Vers gewinnt. . Die Schwalbe, die bei den

1) Hier wie anderwärts mufs Ley zwischen seinen Dekametern ungezählte Halbverse stehen lassen. 
Heiligthümern Jahve's nisten darf, ist glücklich gegen den Sänger, der fern sein muls. ${ }^{*}$ V. 7 ist vielleicht als vermehrter Schlufsvers zu betrachten. Weiter vermag ich hier den Vers nicht zu verfolgen und verweise dafür auf Bickell und Gietmann.

Ps. 101 ist ganz in unserem Schema gehalten, ziemlich allgemein beobachtet ${ }^{1}$ ).

Endlich ist unser Rhythmus besonders häufig in der Reihe der שירי דמעלות, Ps. 120-134, derart, dafs sie nothwendig gemeinschaftlich in Betracht gezogen werden müssen. Es hat mir zwar mit meinen beschränkteren Mitteln nicht gelingen wollen, wie Bickell die ganze Reihe aufser Ps. 132 nach diesem Schema zu erklären ${ }^{2}$ ), noch auch wie Gietmann und Ley bestimmte Psalmen diesem, andere ebenso bestimmt verschiedenen anderen Schemata zuzuweisen ${ }^{3}$ ) : ich will mich darauf beschränken, das thatsächlich nach unserem Schema zu Beobachtende anzuführen.

In $P_{s .} 120$ widerstreben dem Schema nur v. 2 und 5; in beiden liegen Textänderungen zur Herstellung desselben nicht fern.

In Ps. 121 sind v. 1.2 anders gebaut; am Ende von v. 7 darf nicht mit Ley nach LXX ein יהוה eingeschoben werden.

1) Ewald constatirt nur "meistens lange Versglieder", ganz richtig wieder Delitzsch gegenüber den Velleitäten von Ley, Bickell, Gietmann. Vers 1 und 2 a sind nicht ganz in Ordnung. LXX ziehen אופר zu v. 2 und lassen ein ? folgen; der Versbau würde dann be-

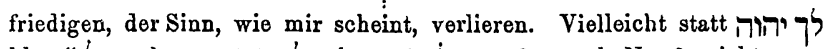

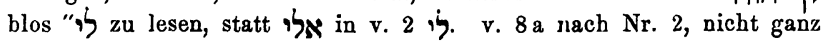
leicht. Daneben 11 gute Verse.

2) Hier bei Bickell das Schema 7, 5, 7, 5 u. s. w., für diese Stücke auch von ${ }^{-G}$ ietman $n$ statt seines hendecasyllabus angenommen.

$\left.{ }^{8}\right)$ Interessant ist es zu sehen, wie Ley 127 und 130 als Hexam. auffafst, die Gietm. nacb 7, 5 construirt; Gietm. 123, 125, 134 als heptas., 128 als hexas., Ley diese sämmtlich als dekam. und pentam. aufführt. 
In Ps. 122 sind die Verse 2, 4 (2 Verse), 6, 7, 9 nach unserem Schema zu lesen, die Verse 1, 3, 5, 8 nicht.

Ps. 123 bietet nur in $\nabla .1$ und Ende v. 2 Spuren. Delitzsch theilt ihn nach dem Caisurenschema.

In Ps. 124 würde die Hälfte der Verse : 1, 2, 5, 6 stimmen.

In $P_{s .} 125$ heben sich die Verse 3 und 4 mit 3 Versen heraus.

Ps. 126 gehört granz unserem Schema an. Es widerstrebt da nur v. $2 \mathrm{~b}$ mit zu langem ersten, v. $6 \mathrm{a}$ mit etwas langem zweiten Gliede.

$P_{s .} 127$ bietet aufser in $2 \mathrm{~b}$ überall Verse nach unserem Schema, nur mehrfach nicht scharf geschnitten, so besonders in v. 1 und 3.

Ps. 128 ist nach unserem Schema gebaut; v. 5 würde aus zwei klaren Versen bestehen, wenn nach dem Haupttheiler noch ein kürzeres paralleles Glied folgte, das auch für den Zusammenhang , wünschenswerth ist.

In Ps. 129 stimmen nicht v. 6 und 8; v. 4 mülste nach $\mathrm{Nr} .3$ getheilt werden.

In Ps: 130 ist v. 2 bis zum Haupttheiler zu v. $1 \mathrm{zu}$ ziehen. Es stimmen dann alle Verse bis auf 6 und 7 .

Ps. 131 stimmt bis auf v. 2, der ein Glied zuriel hat; vielleicht ist כגל עלי נפישי als Glosse zu entfernen. So auch Bickell.

In Ps. 132 lassen sich nur die Verse 1, 4, 9, 12-14 nach unserem Schema lesen, 13 und 14 unsicher genug. Die Absicht scheint hier ausgeschlossen, umsomehr, als auch Ps. 133 nicht ohne künstliche Theilungen ${ }^{1}$ ) .und Ps. 134 gar nicht nach unserem Schema zu lesen sind.

Das Resultat scheint mir folgendes zu sein. Die Psalmen 120 und $121,126-131$, also 8 von 15 sind höchst wahr-

1) Vgl. am besten noch Gietmann S. 130, mit dessen Theilung meine eigene versuchsweise unternommene genau übereinstimmt. 
scheinlich ganz nach unserem Schema gebaut; die vorliegenden Abweichungen wären durch Textverderbnifs oder Nachlässigkeit im Bau zu erklären.

Für dỉe Psalmen 122-125 liegt dieselbe Annahme nahe; doch mülste ihr Text starke Veränderungen erfahren haben.

In den drei letzten Psalmen scheint das Schema nicht angewendet zu sein.

Von anderen Psalmen, deren z. B. Ley (S. 46) noch eine Reihe aufführt, bieten einige wohl nennenswerthe Spuren (so etwa 5, 14, 23, 40) ${ }^{1}$ ), doch kann ich darin die Absicht, unser Schema durchzuführen, nicht erkennen.

Dafs nun alle diese Psalmen mit dem Klagelied.nichts zu thun haben, ist leicht ersichtlich : man darf also fragen, wie sie zu dem Rhythmus kommen, der jener Gattung so eigenthümlich ist. Für die שירי הטעלות, als Wallfahrts lieder aufgefafst, scheint mir die Annahme sich zu empfehlen, dafs nachdem einmal durch das Buch Threni Zion ein classischer Gegenstand für diesen Rhythmus geworden, auch andere Lieder, die mehr oder minder darauf Bezug hatten, sich diesem Gebranche anschlossen und so ein Gegenstück zu dem Buche der Klagelieder in diesem kleinen Buche entstand.

Bezüglich der übrigen Lieder ist auf die stark lehrhafte Haltung von Ps. 19, 8 ff., 101 und auch des betreffenden Stückes von Ps. 65 aufmerksam zu machen.

Ps. 27 schliefst sich einigermafsen dem Stücke Ps. 42 f. an, ebenso Ps. 84.

Im Grunde wird man sagen müssen, dafs in solchen Stücken der Rhythmus des Klageliedes rein formal, als mögliche Form eines Liedes, aufgefalst und gewählt worden ist, ohne auf dèn Gebrauch für einen bestimmten Inhalt

1) Zwischen diesen und den oben aufgenommenen Stücken aus Ps. 65 und 84 ist allerdings wenig Unterschied. 
irgend Rucksicht zu nehmen. Die Möglichkeit solchen Verfahrens kann nicht bestritten werden; die Zeit, von der an sich die Kunstpoesic in dieser Weise populïrer Form bemächtigte, liifst sich nicht bestimmen, doch sind unter den angeführten Psalmen. keine Stücke von unzweifelhaft hohem Alter; auf die völlig gesicherte Beobachtung unseres Schema bei dem Klagelied kann dadurch kein Schatten geworfen werden.

Aber auch an Beispielen für den_anderen Fall, dafs für ein wirkliches Klagelied die gefundene Form nicht angewandt ist, fehlt es nicht, vielmehr lassen gerade die beiden einzigen wirklichen Klagelieder, d. h. Lieder auf den Tod eines Menschen, die im alten Testament vorkommen, II. Sam. 1, 19-27 und 3, 33 f. dieselbe vermissen ${ }^{2}$ ). Bei dem zweiten Stück, dem Klagelied Davids über Abner, kann man zweifeln, ob es wirklich genaue Wiedergabe der Worte, oder nur zusammenfassende Inhaltsangabe ohne jede Rücksicht auf die Form ist; bei dem Klageliede David's über Saul und Jonathan aber ist das unmöglich, das Stück ist eine קינה in extenso, als Kunstwerk auch. der Form nach aufzufassen. Da nun die ältesten uns erhaltenen Stücke nach dem Klageliedschema bei Amos und Hosea, nicht über das 8. Jahrhundert zurückgehen, könnte man annehmen wollen, dals sich diese Klageliedform erst nach David entwickelt habe; aber ich vermag dieses Auskunftsmittel nicht zu ergreifen, weil ich mich versichert halte, dafs, was im 8 . Jahrhundert schon in übertragenem Sinne verwandt werden konnte, als integrirender Bestandtheil der Sitte in hohes Alterthum, auch über David hinauf reichen mufs. Die richtige Erklärung ist eine ganz andere. Wohl haben wir es mit einer קינה zu thun, aber nicht mit der officiellen, stereotypen der

1) Ein Umstand, der gewifs vielfach, namentlich bei Ewald, der richtigen Erkenntnifs bezüglich des Klageliedes im Wege gestanden hat. 
Klageweiber, sondern mit einer exceptionellen, privaten, die sich eben darum auch der populären, gewils sehr kunstlos gehandhabten Form entzieht und in freien, dem Gefühle zwanglos entströmenden Rhythmen sich ergeht. Je weiter hinauf, um so weniger wahrscheinlich, dafs der König sich den Rhythmen der Klageweiber anbequemt. Man darf vielleicht die Hypothese wagen, dafs nie ein eigentliches Klagelied aufser denen der Klageweiber nach unserem Schema gesungen ist; dafs dieses vielmehr aulser der praktischen Verwendung im täglichen Leben nur übertragen zur Anwendung kommen konnte, und keine Spur desselben auf uns gekommen wäre, wenn nicht diese letztere Verwendung bei den Propheten aufgekommen und beliebt geworden wäre.

Mein Material ist erschöpft : es bleiben mir aus dem Dargelegten nur noch einige Folgerungen zư ziehen. $\mathrm{Zu}$ erst zum Buche der Klagelieder. Warum cap. 5 nicht in der Form des Klageliedes geschrieben, ist nun klar : weil es eben kein Klagelied ist, der Dichter hier keine Veranlassung fand, an die Leichenklage zu erinnern. Das hindert umsoweniger, falls man sonst dazu Veranlassung zu haben glaubt, das Lied derselben Hand zuzuschreiben; es reiht sich abschliefsend als Schilderung der traurigen Gegenwart recht gut an die Klage der Vergangenheit an. Um so sicherer rührt cap. 3 nicht von dem Verfasser der übrigen Capitel her. Es repräsentirt ein sehr weit vorgeschrittenes Stadium der Uebertragung, dem die wichtigsten Merkmale der eigentlichen Leichenklage (s. oben) fehlen, das nur noch etwa durch Ps. $42 \mathrm{f}$. belegt werden kann. Die Form ist eben der der zwei ersten Capitel genau nachgeahmt, zugleich aber in einer Aeulserlichkeit übertrieben; der Inhalt mufste wohl schon deshalb ein persönlich-subjectiver werden, weil der Verfasser über den Gegenstand der Capitel 1, 2, 4 nichts neues und nicht aus eigener Anschauung zu berichten wufste. Von der gerühmten und 
bcsonders von Ewald eifrig verfochtenen Einheitlichkeit und Planmiafsigkeit des Buches der Klagelieder bleibt demnach nicht viel librig; nur damit mag es seine Richtigkeit haben, dafs der Verf. von cap. 3, schon von der Sage ausgehend; dafs Jeremia der Verfasser der Lieder sei (vgl. II. Chron. 35, 25), sein Stück in die Mitte einrückte, gerade um dem Ganzen mehr Mannigfaltigkeit und Leben und damit zugleich festeren Halt zu verleihen. Das erste Capitel dem Verfasser von 2 und 4-abzusprechen, wie Thenius thut, sehe ich keinen Grund ").

Viel wichtiger sind die Schlüsse, die von hier aus für die gesammte Poetik der Hebräer sich ergeben, und, wie mir scheint, sehr geeignet, beliebt gewordene falsche Theorieen zu widerlegen. - Wir haben einen bestimmten, scharf geschnittenen Vers erkannt und von allen anderen klar unterschieden; der bewuৎste Gebrauch dieses Verses, im Unterschiede von anders gearteten, zu einem bestimmten Zwecke, reicht in der uns erhaltenen Literatur bis in hohes Alterthum hinauf und mufs im Leben noch viel weiter zurückgreifen. Es ist dies die erste vollkommen gesicherte Beobachtung dieser Art, und wir.werden gut thun, uns daran vor allem zu halten. Der Unterschied dieses Verses von anderen beruht auf der Zahl seiner Glieder und ihrem Längenverhältnifs untereinander ${ }^{2}$ ). Diese Glieder aber werden abgetheilt durch Einschnitte des Sinnes, nicht durch

1) Das oben skizzirte Resultat stützt sich natürlich auch auf andere Gründe, die hier keine Stelle finden.

2) Den Versuch wirklicher Messung der einzelnen Versglieder nach einem bestimmten Malsstabe, Silbe, Versfufs, Hebung, Wort, würde ich selbst dann hier unterlassen, wenn ich die Ueberzeugung theilte, dafs hier und sonst in der hebräischen Poesie nach genauem Metrum gearbeitet wäre. Ich verweise dafür nur auf Auge und $\mathrm{Ohr}$, die hier jedenfalls ausreichen. Viel liegt mir daran, eine hier hoffentlich erreichbare Einigung nicht sogleich wieder durch mehr oder minder subjective Theorieen zu gefährden. 
ein vom Sinne unabhängiges, rein formales Metrum : Formeinheit und Sinneseinheit, wie immer die erstere begriffen werden möge, decken sich. Es ist deshalb unzulässig, Metra zu bilden, in denen die Verszeilen einfach nach irgend einem Princip abgezählt werden, ohne Rücksicht auf den Sinn, ein Verfahren, wie es besonders von Bickell noch häufig zur Anwendung gebracht wird. Ferner gehört es zur poetischen Form dieses Verses, dal's jedesmal zwei Glieder von bestimmtem Verhältnifs nach Sinn und Mals sich zu einer abgeschlossenen Einheit verbinden. Der sogenannte Parallelismus ist also in diesem Verse nicht etwa „das rhetorische Grundgesetz der höheren Rede im Hebräischen ${ }^{* 1}$ ), sondern recht eigentlich poetische Form, denn auf dem Mafs-Verhältnifs der parallelen Glieder zu einander beruht der specifische rhythmische Effect dieser uralten Form des Klageliedes. Wollte man abềr behaupten, unser „Vers" sei gar nicht als solcher, sondern als Stichos zu betrachten, der nachträglich durch eine Cäsur getheilt sei, so ist der Gegenbeweis zu erbringen durch die grolse Anzahl von Klageliedversen, die wirklichen Sinnesparallelismus aufweisen, freilich der Natur der Sache nach meistens derart, dals nicht selbständige, sondern zusammengezogene Sätze nebeneinanderstehen, was an sich den Parallelismus nur um so enger gestaltet ${ }^{2}$ ). Interessant ist hier $\mathrm{de}$ Wette's Anmerkung ${ }^{3}$ ), dals in dem Buche der Klagelieder der „blofs rhythmische Parallelismus" am meisten

1) vgl. z. B. MerX, Hiob S. LXXVI.

2) Vgl. Thr. 1, 2 a. c. 3 a. b. 4 a. b. (c.) 5 a. 7 c. ( 8 a. b.) c. 9 a. b. (c.) 10 b. 11 a. (b. c.) 13 a. b. c. 14 a. b. (c.) 16 a. b. (c.) 17 a. 18 b. $19 \mathrm{a}$ (c.) 20 a (b) c. 21 a (b.) c. 22 (a.) c. In Jes. 14 sind auszunehmen als Verse, die nur einen Satz bilden, nur 9 a. c. 12 a. b. 18. 19 a. b. 20a. c. 21 a - Die eingeklammerten Ziffern bezeichnen Verse, in denen kein eigentlicher Parallelismus, sondern Fortschritt des Gedankens in einem neuen Satze stattfindet.

3) Psalmen, 4. Aufl. S. 55. 
hervortrete, und der "Parallelismus des Gedankens", wenn er vorkomme, meistens der Unterparallelismus eines Gliedes für sich sei. Dieses Vorkommen, von de Wette der Häufigkeit nach nur bedeutend unterschätzt, beweist eben am besten, dafs wir es hier nicht mit Versgliedern, sondern (wenigstens ursprünglich) mit selbständigen Versen zu thun haben. Und diese Thatsache wird unumstöfslich durch die Gewilsheit, dafs unsere Verse gesungen worden sind und gerade die wiederkehrende zweitheilige, aus längerem Aufund kürzerem Abgesang bestehende MIelodie es gewesen sein mufs, die diese regelmäfsige Wiederkehr des Versrhythmus bedingrte. Nicht mit je 2 oder mit je 3 Versen war die Melodie zu Ende, sondern mit jedem einzelnen unserer Verse; denn in Thr. 4 vereinigt der Buchstabe je 2 , in Thr. 1 und 2 je 3 Verse, in anderen Stücken schliefsen sich noch andere Summen, und zwar höchst schwankende und verschiedene an einander an, und doch wollen alle diese Stücke denselben eintönigen Rhythmus des populären Klageliedes wiedergeben. Vielleicht unbewufst hat denn auch unser Klageliedvers selbst die entschlossensten $\mathrm{Me}$ triker in nicht geringe Verlegenheit gebracht. Ley, der seine Strophen auf ganze Verse, nicht auf Stichen aufbaut, erkennt in den Threni einen "elegischen Pentameter", während er denselben Vers sonst zum Dekameter macht, obne doch dazwischen die pentametrischen Halbzeilen loszuwerden. Bickell, der mit Stichen operirt, erkennt umgekehrt in Thr. 1-4 ein metrum dodecasyllabum, während er für die Psalmen $(14,19,27,48,84,101)$ ein Schema 7, 4, 7, 4, für die „psalmi graduales" und einige andere 7, 5, 7, 5 statuirt. Ebenso Gietmann, nur dafs er dem versus hendecasyllabus der Klagelieder noch einige Stücke zuweist, unter anderen auch Ps. 14, 19, 27, 84, 101 : zum Beweise- der Identität beider Metra. Es bleibt dabei, der Vers des Klageliedes schliefst sich in einmaligem Eintritt des längeren und des kürzeren Gliedes ab. 
Der zu Grunde liegende feste zweigliedrige Parallelismus aber stellt unseren Vers dem allgemeinen Verse mit gleichschwebendén Gliedern an die Seite; der Klageliedvers mufs durch Modification des letzteren entstanden sein. Durch regelmäfsige Verstümmelung des zweiten Gliedes in einem gewöhnlichen Verse ist dieser für das Klagelied in so hohem Malse geeignete Vers mit seinem echoartigen Nachhall, dem immer wiederholten Hinsterben des Rhythmus, geschaffen. Ist nun der Parallelismus in dem Verse des Klageliedes poetische Form und nicht blol's rhetorischer Charakter, so ist er es auch in dem gleichschwebenden und in anders modificirten hebräischen Versen. Im Verse wird sich die einfache Melodie des alten hebräischen Liedes überhaupt ebenso abgeschlossen haben, wie dies für das Klagelied bewiesen ist, und damit ist dem neuerdings so beliebten Verfahren, den Stichos als die metrische Einheit hinzustellen, um daun desto ungestörter rhythmisch werthlose Strophen nach eigenstem Ermessen zu bilden, wie mir scheint, das Urtheil gesprochen ${ }^{\mathbf{1}}$ ).

Aber auch hier möchte ich nicht nur negiren, sondern, soweit es an mir ist und mein Gegenstand es mit sich bringt, auch aufbauen. Und dazu dürfte nicht leicht ein anderer Ausschnitt dieses Gebietes so geeignet sein, wie dieser. Der herrschende hebräische Vers mit seinen gleichschwebenden Gliedern ist zur Bildung von Strophen, von höheren rhythmischen Einheiten, der denkbar ungeschickteste. Er ist es darum, weil er sich als schon zusammengesetzte Einheit nach innen hin selbst so fest abschliefst und seinen eigenen Schwerpunkt schafft, dafs er einen Anschlufs über sich hinaus nicht nur nicht verlangt, sondern eher abweist. Daher zum guten Theil die überwiegend

1) Höchst erfreulich war mir, neben anderen gelegentlichen Aeufserungen von Fachgenossen, die derbe Skeptik, mit der Gietmann (S. $35 \mathrm{f}$.) die ganze Strophensucht abweist.

Zeitschrift f. d. alttest. Wiss. Jahrgang \&. 1882. 
gnomische, fast aphoristisch klingende Haltung hebräischer Poesie, der Hangel einer eigentlichen epischen Kunstform; daher das immer wiederholte Bemühen eifriger Strophentheoretiker, den Hemmschuh des Parallelismus loszuwerden. Es ist deshalb in hohem Grade unwahrscheinlich, dafs Strophen, die den Namen verdienen, zu den ursprünglichen Bildungen hebräischer Poesie gehören. Etwas besser steht es in dieser Hinsicht mit dem Klageliedverse, wie wir denselben in einer so grofsen Reihe von Stücken verfolgt haben. Der starre centrale Bau des Verses ist hier durchbrochen, das Gleichgewicht aufgehoben, weil der Theilpunkt sich nicht mehr mit dem Schwerpunkt deckt; der Vers eilt auf das Ende zu, weist über sich hinaus und erstrebt ein neues Gleichgewicht durch Anschmiegung an einen gleichen Vers, nach demselben Gesetze, das die Glieder zum Verse zusammenfügte ${ }^{1}$ ). Daza drängte noch der weitere Umstand, dafs es, bei umfangreichen Gedichten immer schwerer werden mulste, das kürzere Glied zur vollwichtigen Parallele des ersten auszubilden, während zu gleicher Zeit der scharfe, unverbrüchliche Zuschnitt der beiden Glieder einen unmittelbar rhythmischen Eindruck machte und den Sinnesparallelismus kaum mehr vermissen liefs. So würde das zweite kürzere Glied häufig blofs dadurch gebildet, dals ein Satztheil - Subject, Prädicat, Object, adverbiale Bestimmung - aufgespart und in auffallender Weise an das Ende geschoben wurde, wie sich die Beispiele dafür in den besprochenen Stücken zahlreich finden. Solche rhythmisch vollständigen Verse verlangten aber dem Sinne nach parallele Ergänzung, und so schlossen sich wohl von selbst, ohne irgend welche Absicht der Bildung höherer poetischer Einheiten, meistens zwei oder mehr Klageliedverse enger an einander an, als dies sonst der

1) Vgl: Hupfeld,, Psalmen, 2. Auf. S. 22 ff. 
Fall zu sein pflegt. Wie ungezwungen dies meistens geschieht, mag schon aus den oben angeführten, so sehr verschieden" ausgefallenen Versuchen, Jes. 14 strophisch abzutheilen, geschlossen werden. Aber hier liegen dennoch die Anfänge wirklicher Strophenbildung vor. Was bei fast allen jenen sogenannten Strophen fehlt, ein neues Formmittel für die Bildung einer neuen formalen Einheit, das ist hier geboten in der Herstellung des Gleichgewichtes durch Zusammenfügen mehrerer solcher hinkenden Verse. Dafs dieses Mittel einige Male auch mit Bewufstsein zu diesem Zwecke benutzt worden ist, beweisen die Capitel 1, 2, 4 der Klagelieder. Hier ist es nicht wesentlich der alphabetische Buchstabe, der den strophenartigen Eindruck der masorethischen Verse hervorruft : er kommt nur hinzu, um die Abschnitte für das Auge zu bezeichnen. Die doppelte Gliederung der Form und der Parallelismus des Sinnes zwischen den einzelnen Versen, der in jenen Capiteln schön durchgeführit ist, lälst uns hier die höhere poetische Einheit erkennen. Dasselbe Resultat ist in Ps. 42. 43 auf andere Weise gewonnen. Eine gewils ursprünglich in allen 3 Abschnitten ganz gleiche Zahl von Versen nach unserem Schema ist abgeschlossen durch einen gleichlautenden Refrainvers, der, anders gestaltet, scharf von dem Körper des Liedes sich abhebt. So entsteht hier ein Eindruck, ähnlich dem unserer mittelhochdeutschen dreitheiligen Strophe mit gleichen Stollen und im Bau abweichendem Abgesang : ein so vollendetes Formganzes, wie wir es in den uns erhaltenen Resten hebräischer Poesie nicht wiederfinden. Aber gerade dals uns nur so vereinzelte klare Beispiele eines erfolgreichen Bestrebens, Strophen zu bilden ${ }^{1}$ ), und diese unter den denkbar günstigsten Um-

1) Dals auch sonst hie und da mit geringeren Mitteln weniger erfolgreiche Ansätze gemacht sind, soll nicht geleugnet werden. 
stïnden, begegnen, berechtigt nicht nur, sondern nöthigt uns zu der gröfsesten Behutsamkeit auf diesem Gebiete, und ein frommer Wunsch mafs vor allem im Interesse der Sache ausgesprochen werden : dafs man mit strophischen Theorieen doch solange zurückhalten möge, bis wir in das Wesen des hebräischen Verses tiefer eingedrungen sind, als das bisher der Fall ist.

Ein Beitrag zur Lösung dieser Aufgabe will der vorliegende Aufsatz sein.

Erst nach Abschlufs dieses Aufsatzes wurde mir bekannt : Neteler, Grundzüge der hebräischen Metrik der Psalmen. Münster 1879. Der Verf. tritt der Hauptsache nach in die Fulstapfen Ley's, indem er die masorethische Aussprache und Accentuation beibehält, die Tonsilben zählt, den masorethischen Vers, wenigstens principiell, zur metrischen Einheit macht. Das Resultat seiner Zählungen ist, trotzdem er in seinen Regeln grofsen Spielraum läfst, ein wenig befriedigendes und dazu oft genug nach des Verf. eigenen Regeln anzufechten. Wie kühn er gelegentlich verfährt, mag Psalm 2 zeigen (S. 10), in welchem er das erste Wört von v. 2 , die 2 ersten von v. $8 \mathrm{zu}$ dem vorhergehenden Verse zieht, v. 12 vom Athnach an als selbständigen Vers von drei Füfsen abtrennt. Von den in vorliegender Arbeit behandelten Stücken hat er die Psalmen 121, 122, 127, 128, 129 berücksichtigt (S. 21 f.), doch ist -seine Analyse für uns werthlos, da er das Verbältnifs der Stichen zu einander gar nicht in Erwägung zieht, ja denselben nach S. 6 metrische Geltung ganz abzusprechen scheint. - Zu S. 12 Anm. 2 mufs ich berichtigen, dals nur die Uebersetzung von Jes. 14 von Kamphausen herrührt, die dort angeführte-Strophenabtheilung dagegen von $B u n$ s en selbst. 